RECORDS ADMINISTRATION

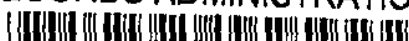

$\mathrm{R} 0139047$

\title{
SOLID WASTE COMBUSTION FOR ALPHA WASTE INCINERATION
}

D. I. ORLOFF

E. I. du Pont de Nemours \& Co. Savannah River Laboratory

Aiken, SC 29808 
This report was prepared by E. I. du Pont de Nemours and Company (Du Pont) for the United States Department of Energy under Contract DE-AC09-76SR00001 and is an account of work performed under that Contract. Neither the United States, the United States Department of Energy nor Du Pont, nor any of their employees, makes any warranty, express or implied, or assumes any legal liability or responsibility for the afiuracy, completeness, or usefulness of any information, apparatus, product, or process disclosed herein, or represents that its use will not infringe privately owned rights. Reference herein to any specific commerical product, process, or service by trade name. mark, manufacturer, or otherwise does not necessarily constitute or imply endorsement, recommendation, or favoring of same by Du Pont or by the United States (iovernment or any aqency thereof. The views and opinions of authus expressed herein do nol necessurily state 4 reflect those of the United States Government or any agency thereot.

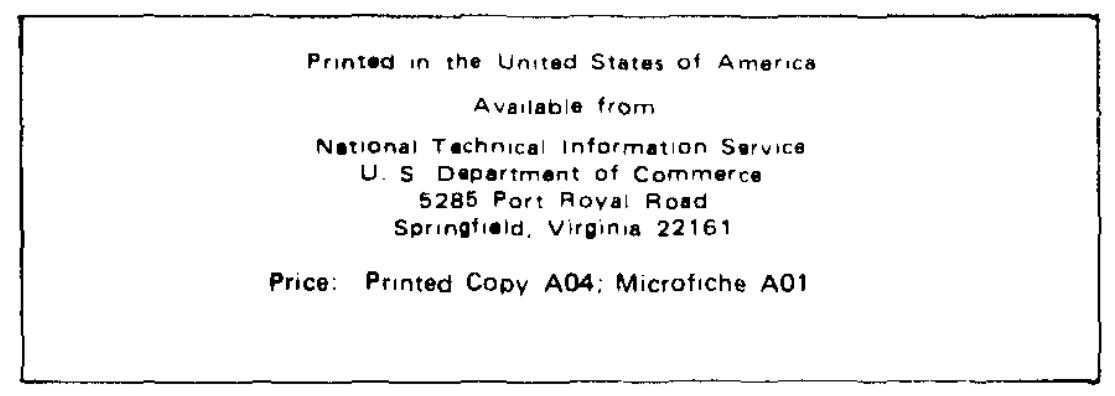




\section{DP-1570}

Distribution Category: UC-70

\section{SOLID WASTE COMBUSTION FOR ALPHA WASTE INCINERATION}

\section{I. ORLOFF}

Approved by

E. L. Albenesius, Research Manager

Waste Disposal Technology Division

Publication Date: February 1981

E. I. du Pont de Nemours \& Co. Savannah River Laboratory Aiken, SC 29808 
Radioactive waste incinerator development at the Savannah River Laboratory has been augmented by fundamental combustion studies at the University of South Carolina. The objective was to measure and model pyrolysis and combustion rates of typical Savannah River Plant waste materials as a function of incinerator operating conditions. The analytical models developed in this work have been incorporated into a waste burning transient code. The code predicts maximum air requirement and heat energy release as a function of waste type, package size, combustion chamber size, and temperature: Historically, relationships have been determined by direct experiments that did not allow an engineering basis for predicting combustion rates in untested incinerators. The computed combustion rates and burning times agree with measured values in the Savannah River Laboratory pilot ( $1 \mathrm{lb} / \mathrm{hr}$ ) and full-scale $(12 \mathrm{lb} / \mathrm{hr})$ alpha incinerators for a wide variety of typical waste materials. 
CONTENTS

Introduction and Background 5

Summary 6

Laboratory-Scale Incinerator (Test Unit) 6

Pyrolysis and Combustion Rate 6

off-Gas Sampling and Analys is 18

Experimental Procedures 20

Pyrolysis and Combustion Rates 20

off-Gas Sampling and Analysis 22

Experimental Data 22

Laboratory-Scale Pyrolysis and Combustion Rates 22

ICTF Combustion Rates 26

Analytical Models 26

Pyrolysis Rate 26

Combustion Rate 33

Off-Gas Composition 41

Stoichiometric Model 41

Discussion of Results and Conclusions 43

Pyrolysis in the Laboratory-Scale Incinerator 43

Combustion in the Laboratory-Scale Incinerator 47

Combustion in the Primary of the ICTF 47

off-Gas Analysis from the Laboratory-Scale Incinerator 54

Preliminary Pyrolysis Experiments 54

Combustion of Polyethylene 54

Nomenclature $\quad 61$

Acknowledgments 64 .

References 65 


\section{INTRODUCTION AND BACKGROUND}

The development of technology for the incineration of combustible solid radioactive wastes is of current national interest. Incineration development at the Savannah River Laboratory (SRL) has been augmented by fundamental combustion studies at the Center for Industrial Research at the University of South Carolina.

The design of incinerators for the volume reduction of radioactive combustible solid waste requires the determination of maximum heat release rates and air requirements for limiting case waste materials. This report discusses the development of an analytical model which predicts burning rates and off-gas composition in the Savannah River Laboratory's Incinerator Components Test Facility (ICTF) primary combustion chamber.

The objectives of the present work were to

1. Measure and model pyrolysis ${ }^{2}$ and burning rates of meltingnoncharring waste polymers (polyethylene and latex) and a nonmelting-charring waste polymer (cellulose) as a function of incinerator operating conditions. These conditions included incinerator primary chamber wall temperature and primary chamber air upstream Reynolds number.

2. Compare the predictions of the burning rate model with experimental ICTF burning rate data supplied by SRL.

3. Measure and interpret off-gas products from the combustion of polyethylene in the laboratory-scale incinerator. 


\section{SUMMARY}

The analytical model requires thermophysical data which are specific to each waste material. To obtain these data, and test the analytical model, a laboratory-scale incinerator was developed. Experiments were conducted on the following typical solid waste materials: plastic bags (polyethylene), rubber gloves (latex), and atomic wipes (cellulose). Experimentally measured and predicted burning rates in the laboratory-scale incinerator agreed for polyethylene (Figure 1). The burning rate prediction for latex and cellulose provides an upper bound to the experimental rates (Figures 2 and 3 ). To test scaling assumptions in the analytical model, burning times on the ICTF were measured and used to generate average experimental burning rates as a function of primary temperature and waste type. The analytical model was used to predict burning rates in the ICTF, and these were compared to the experimental values (Figures 4,5 , and 6 ). The values for burning rates for polyethylene and latex agree, and the theory provides an upper bound for the case of cellulose.

In addition to predicting the burning rate in the ICTF primary combustion chamber, the analytical model also predicts the mass fraction of off-gas from the primary. Typical ICTF operating conditions of high temperature and low primary air flow favor fuelrich combustion in the primary (Figures 7 and 8 ). Such operating conditions necessitate additional combustion in the incinerator secondary chamber. The amount of secondary combustion air required may be determined from the mass fraction of unburned fuel in the primary chamber off-gas and the chemical identity of the unburned fuel. Off-gas analysis as a function of time on the laboratoryscale incinerator, for the case of burning polyethylene, showed that the process will become fuel rich (Figure 9). Similar results are often observed from oxygen percent vs. time measurements in the secondary of the ICTF. The infra-red spectra of a sample taken on the laboratory-scale incinerator is shown in Figure 10. The unburned fuel in the off-gas from the combustion of polyethylene in the incinerator primary chamber is composed of intermediate molecular weight hydrocarbons (toluene, hexane, and benzene) and lower molecular weight hydrocarbons (methane, ethylene, and acetylene).

\section{LABORATORY-SCALE INCINERATOR (TEST UNIT)}

\section{Pyrolysis and Combustion Rate}

A laboratory-scale incinerator was designed to provide the required burning rate data. A schematic of the laboratory-scale incinerator and support equipment is shown in Figure 11 . The test unit provided a controlled air mix and mass flow rate of gas over the heated waste polymer sample. 


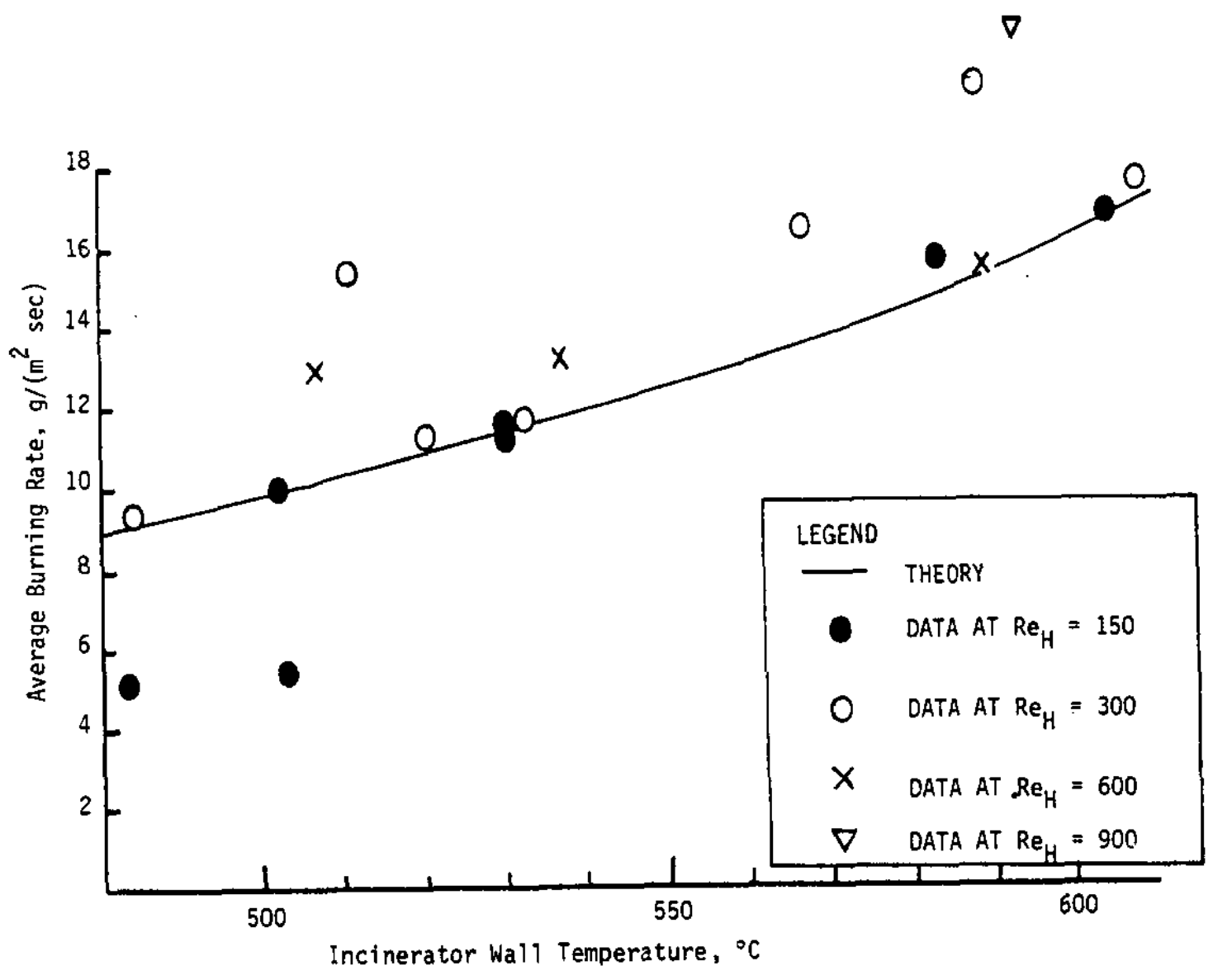

FIGURE 1. Average Burning Rate of Polyethylene in Air 


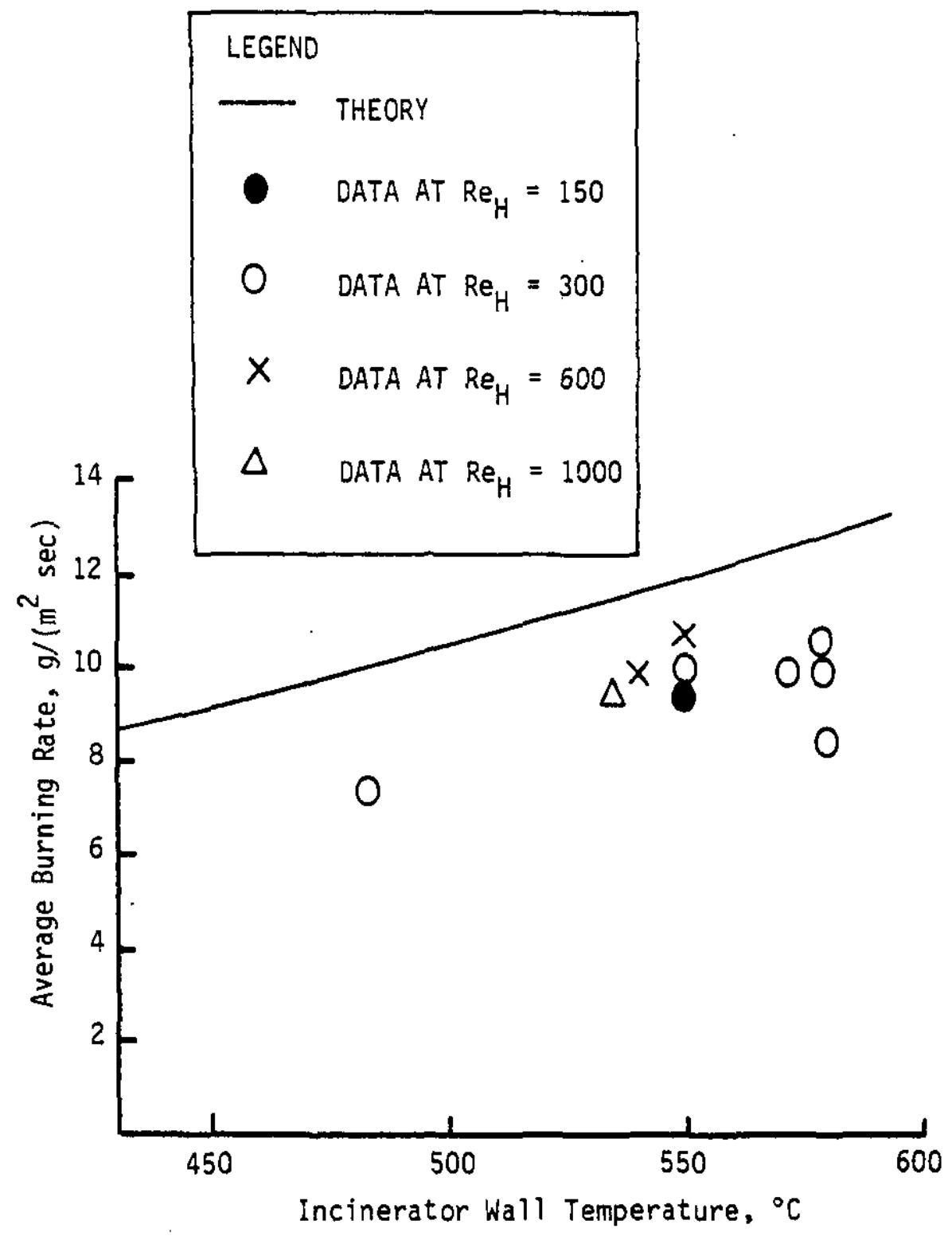

FIGURE 2. Average Burning Rate of Cellulose in Air 


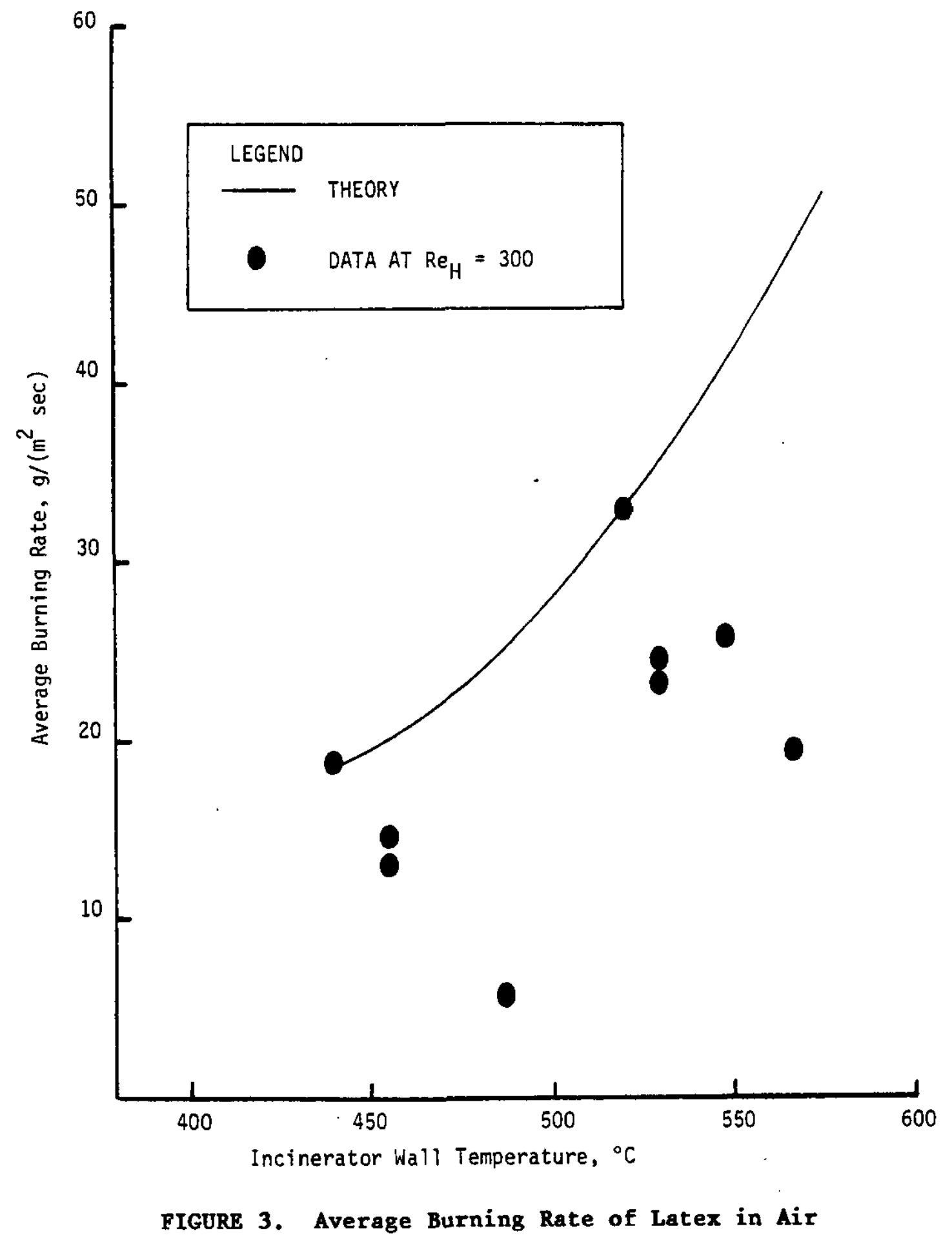




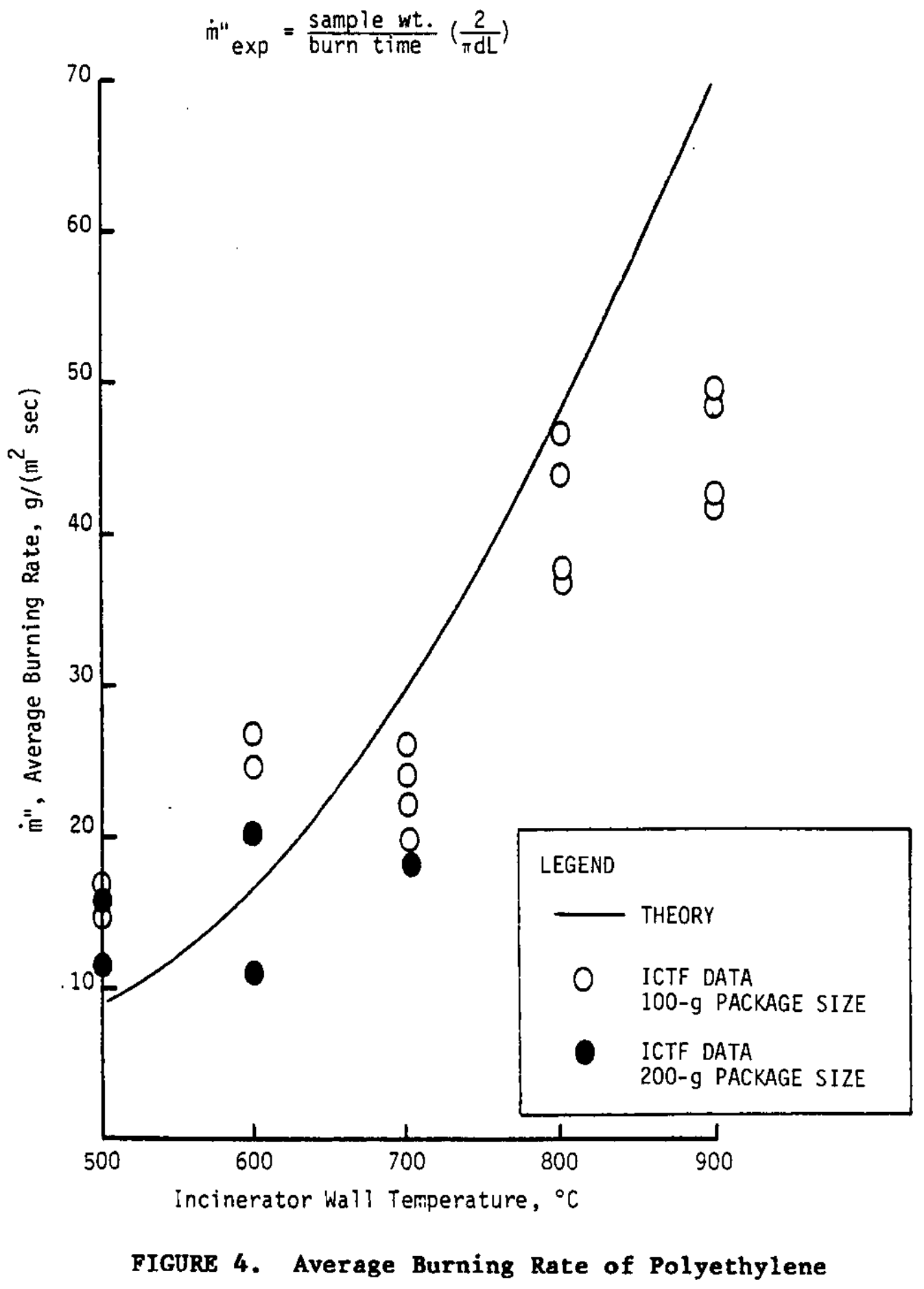




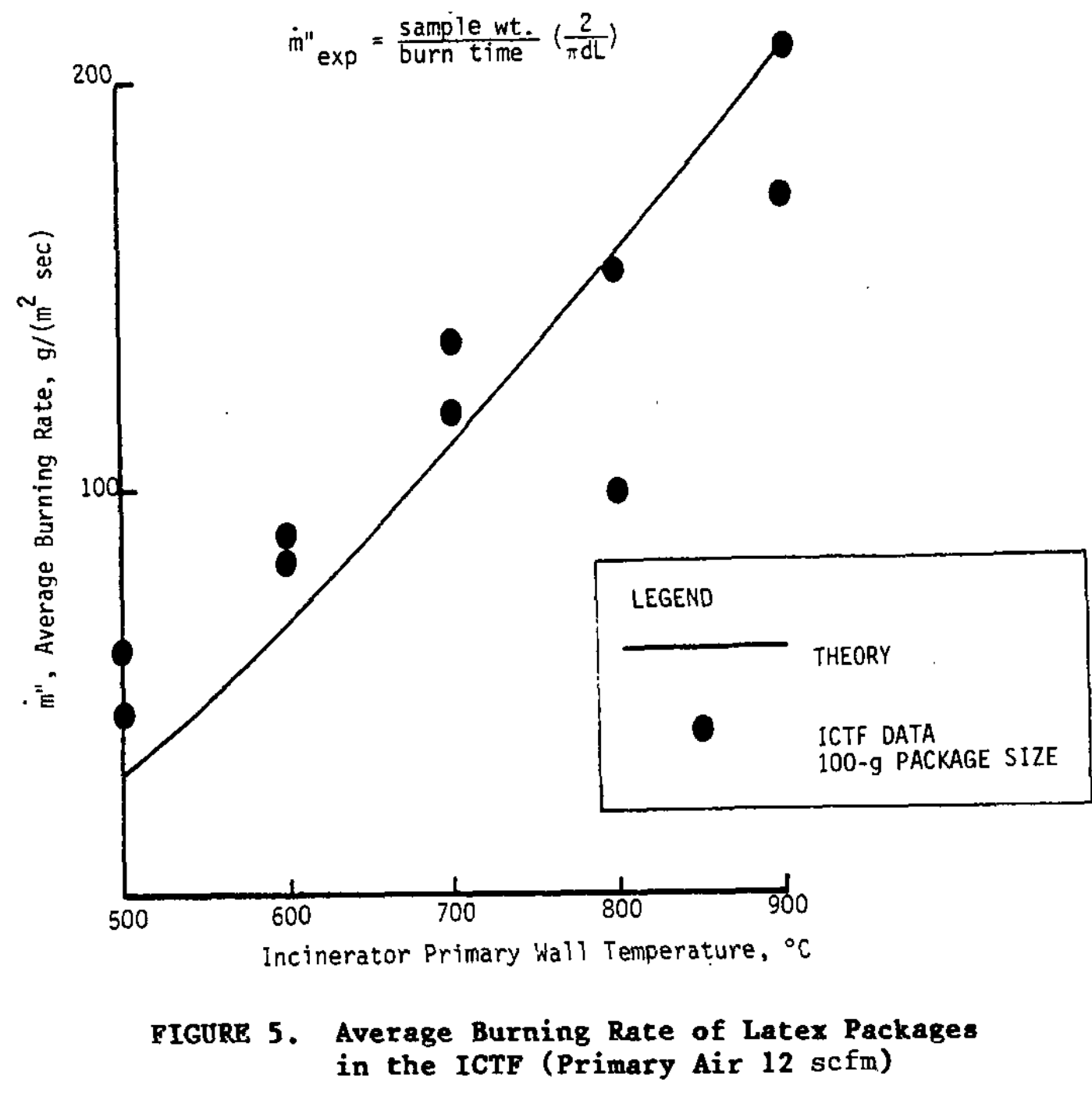




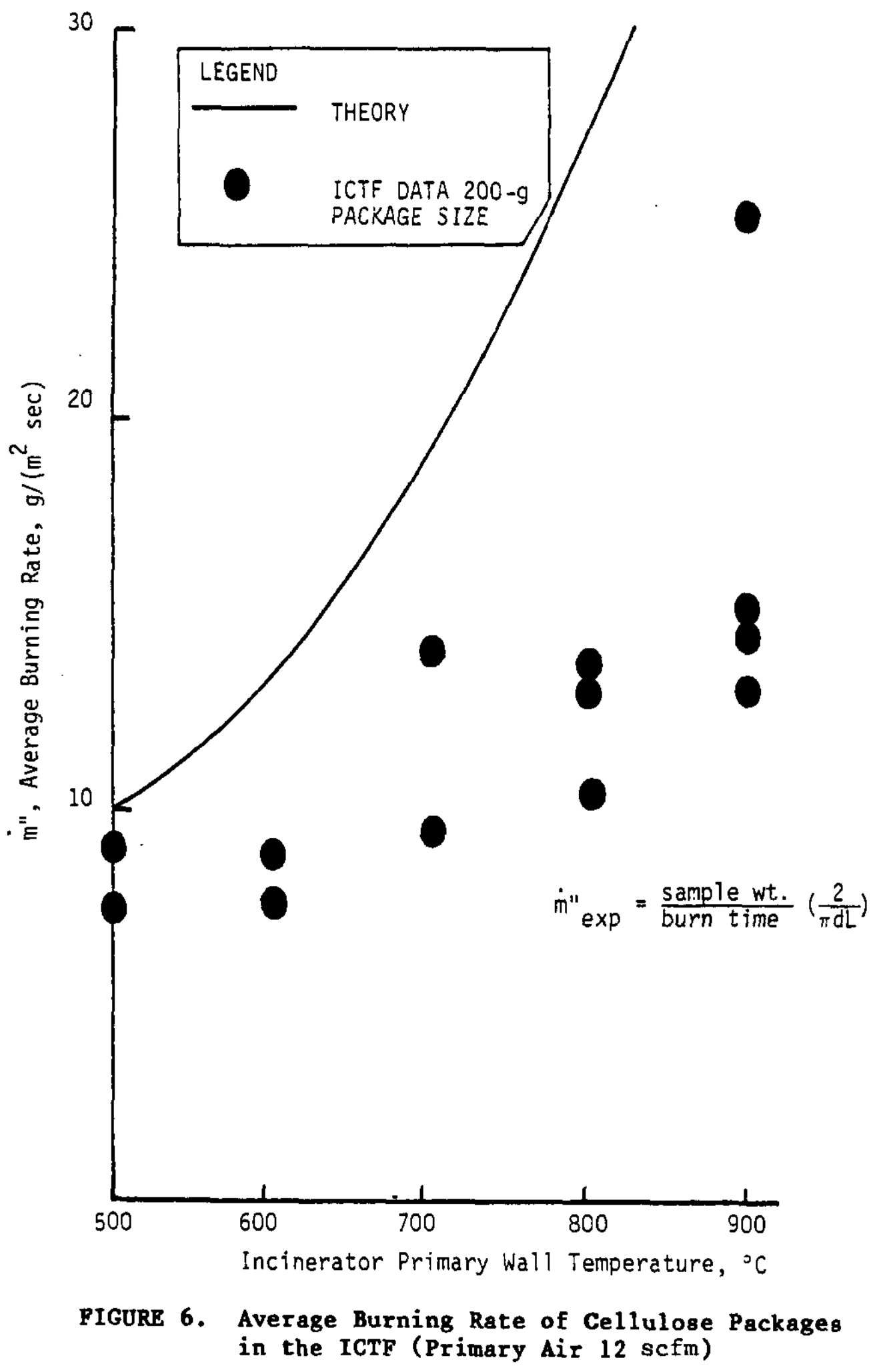




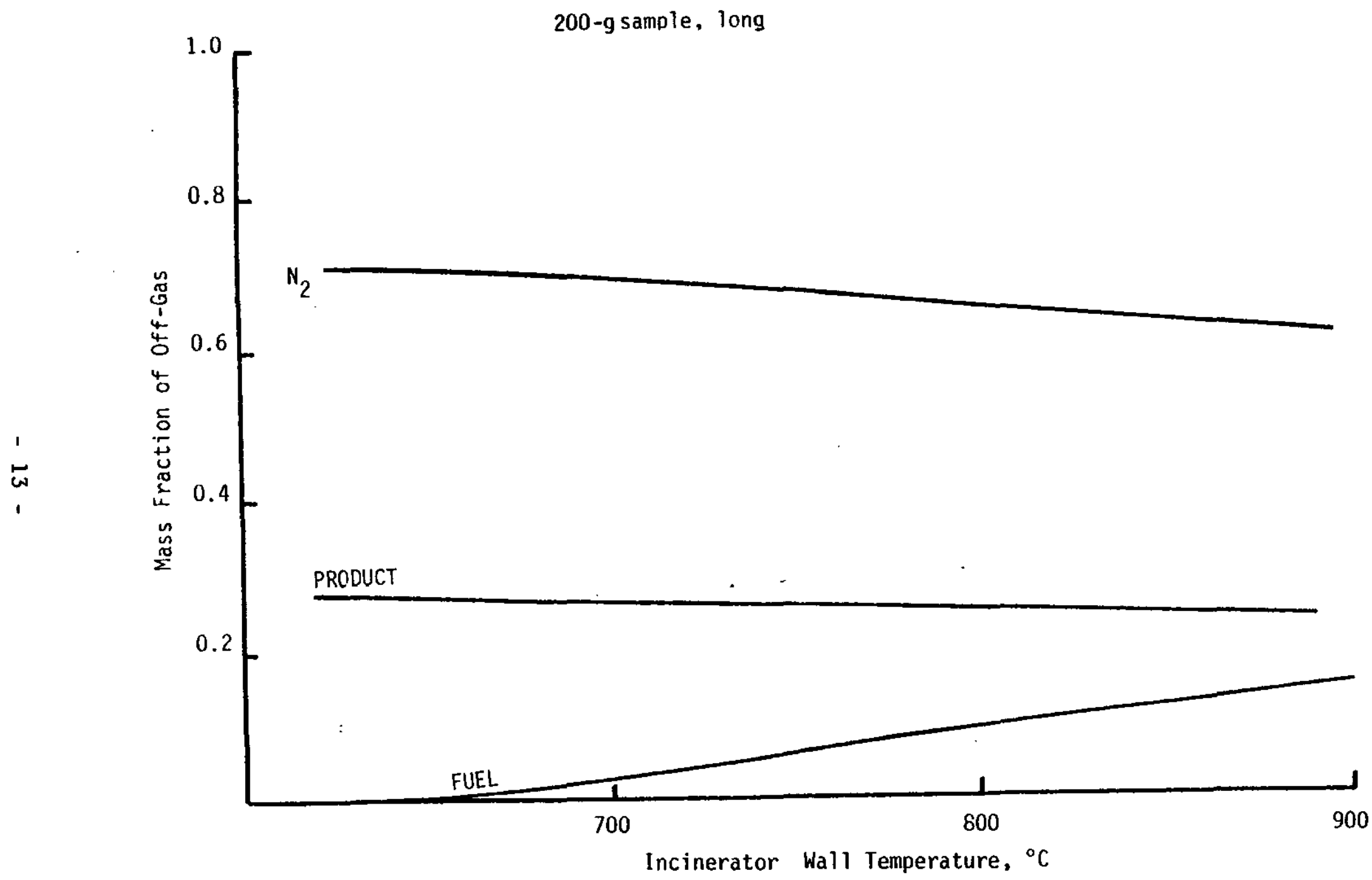

FIGURE 7. Off-Gas Theoretical Prediction of Polyethylene Combustion at $\mathrm{Re}_{\mathrm{H}}=2000$ in ICTF 


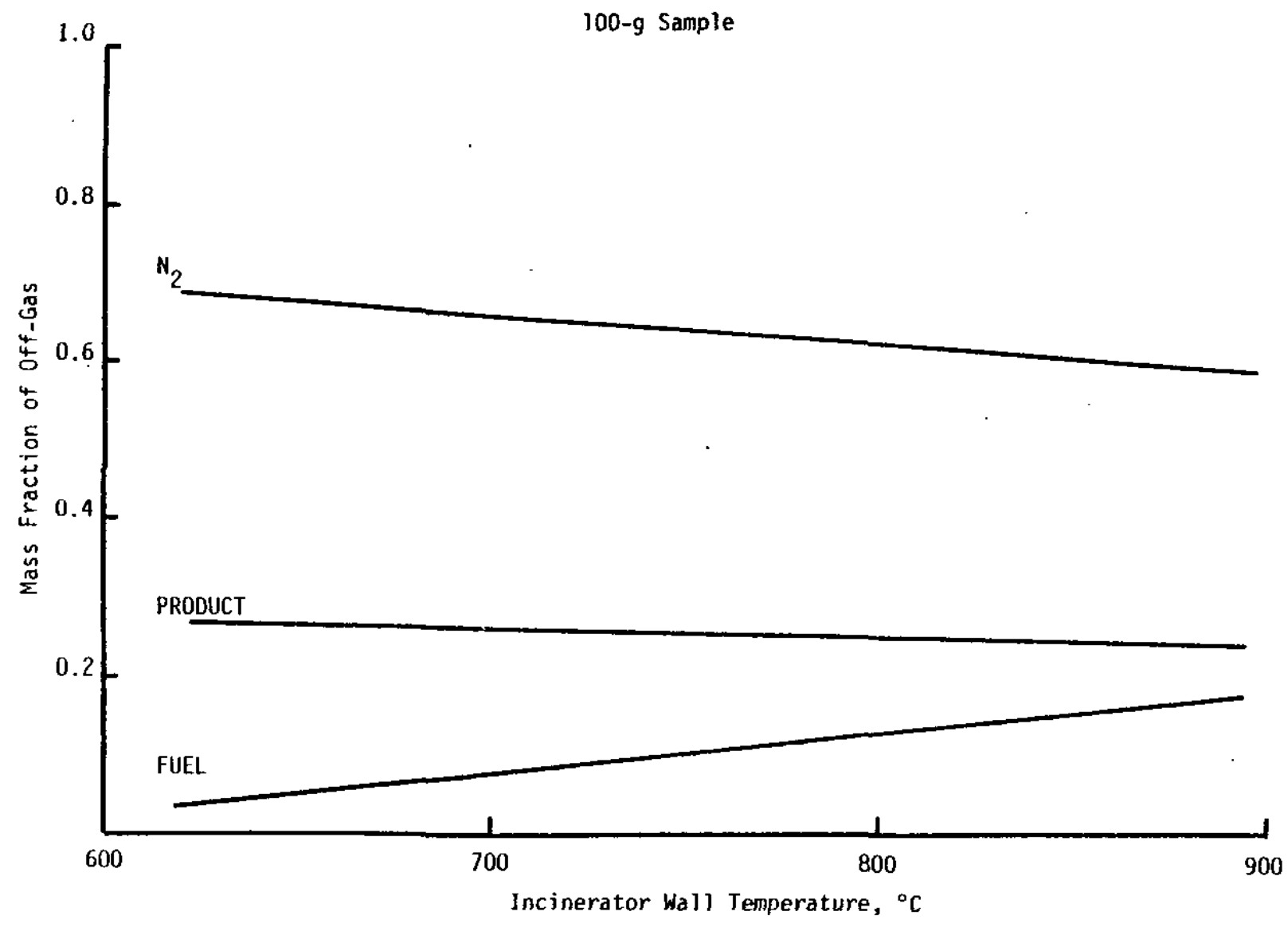

FIGURE 8. Off-Gas Theoretical Prediction Latex Combustion at $\operatorname{Re}_{\mathrm{H}}=2000$ in ICTF 


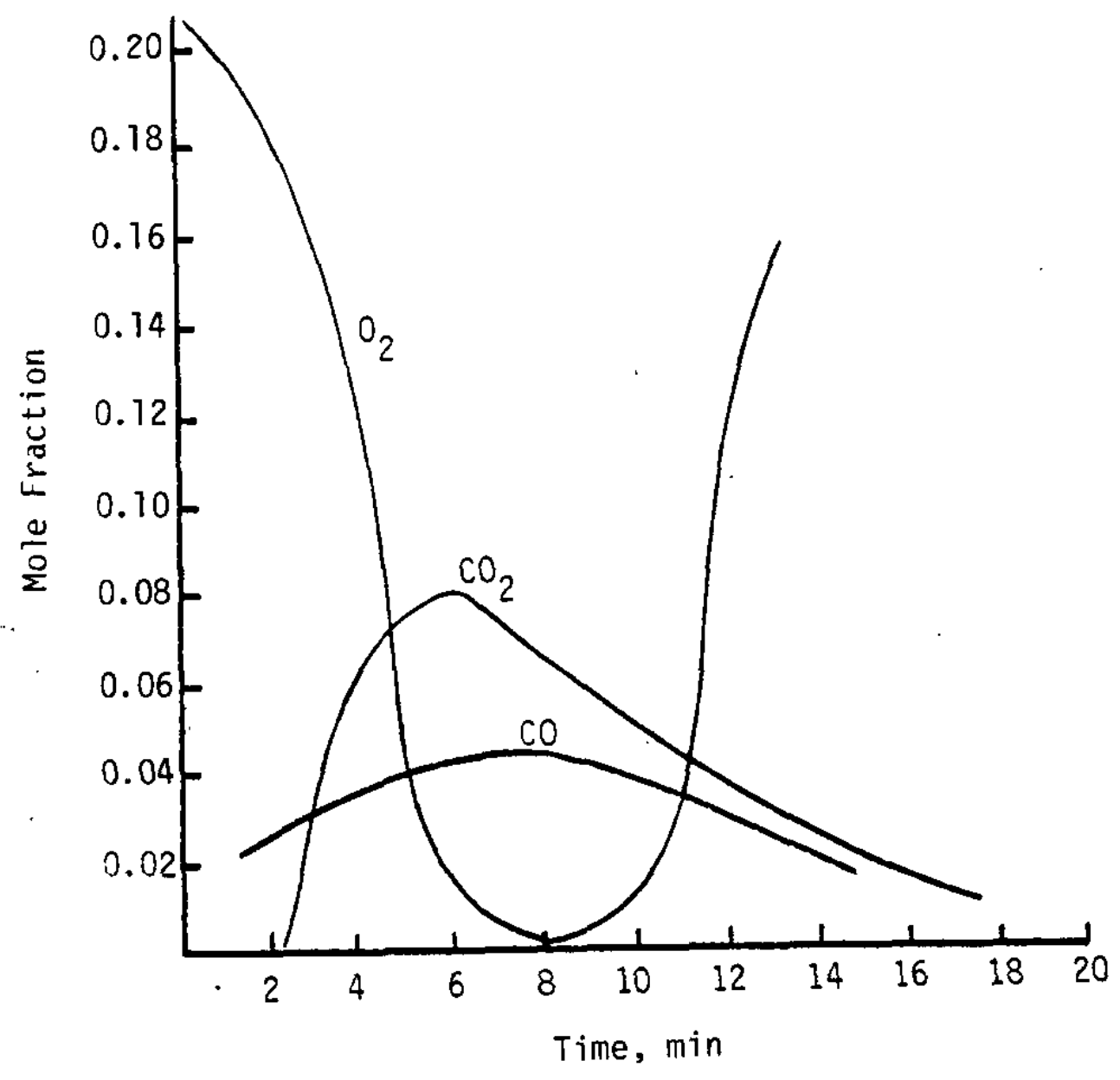

FIGURE 9. Off-Gas Analysis of Laboratory-Scale Combustion of Polyethylene 


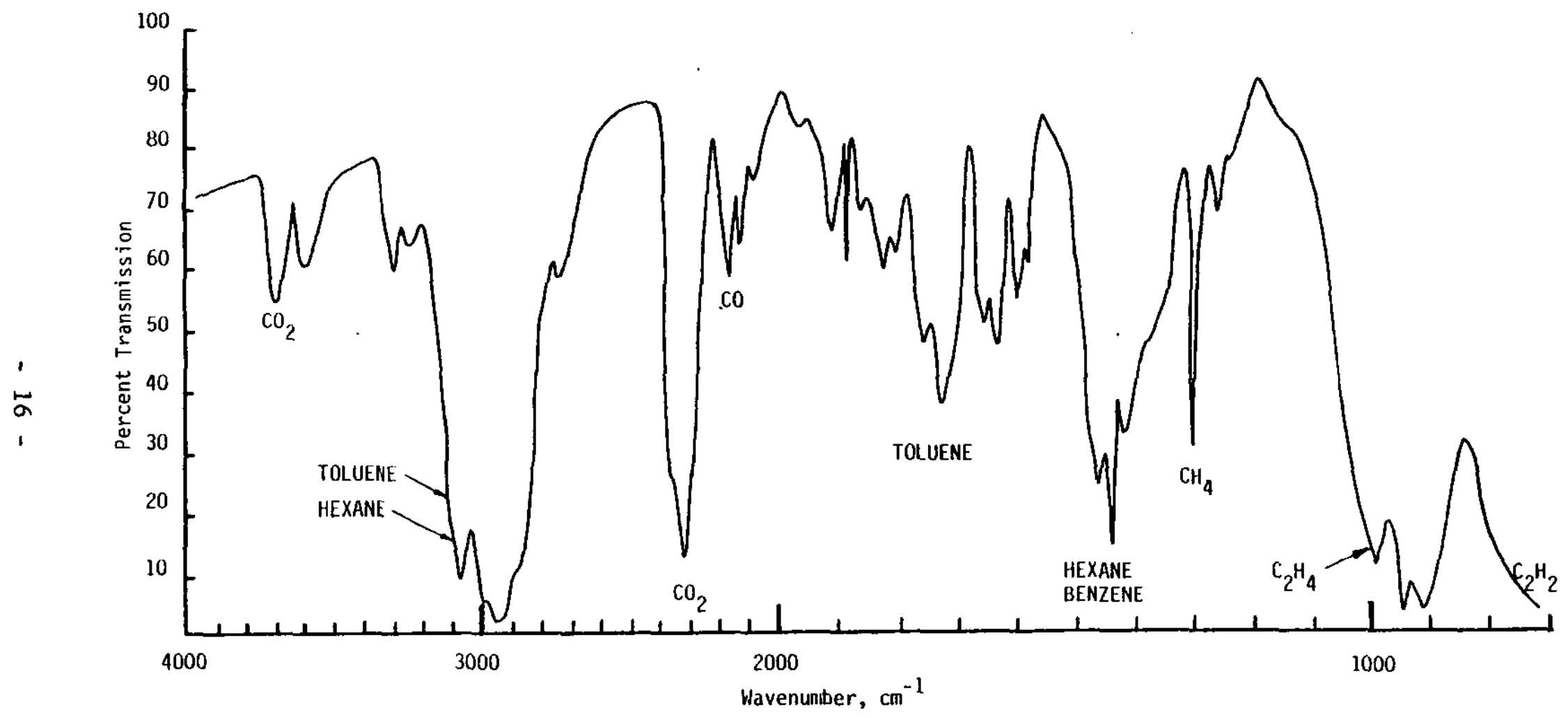

FIGURE 10. Infrared Spectra of Laboratory-Scale Sample of Polyethylene Combustion Off-Gas

$\left(\operatorname{Re}_{\mathrm{H}}=100\right)$

$\left(T_{w}=530^{\circ} \mathrm{C}\right)$ 


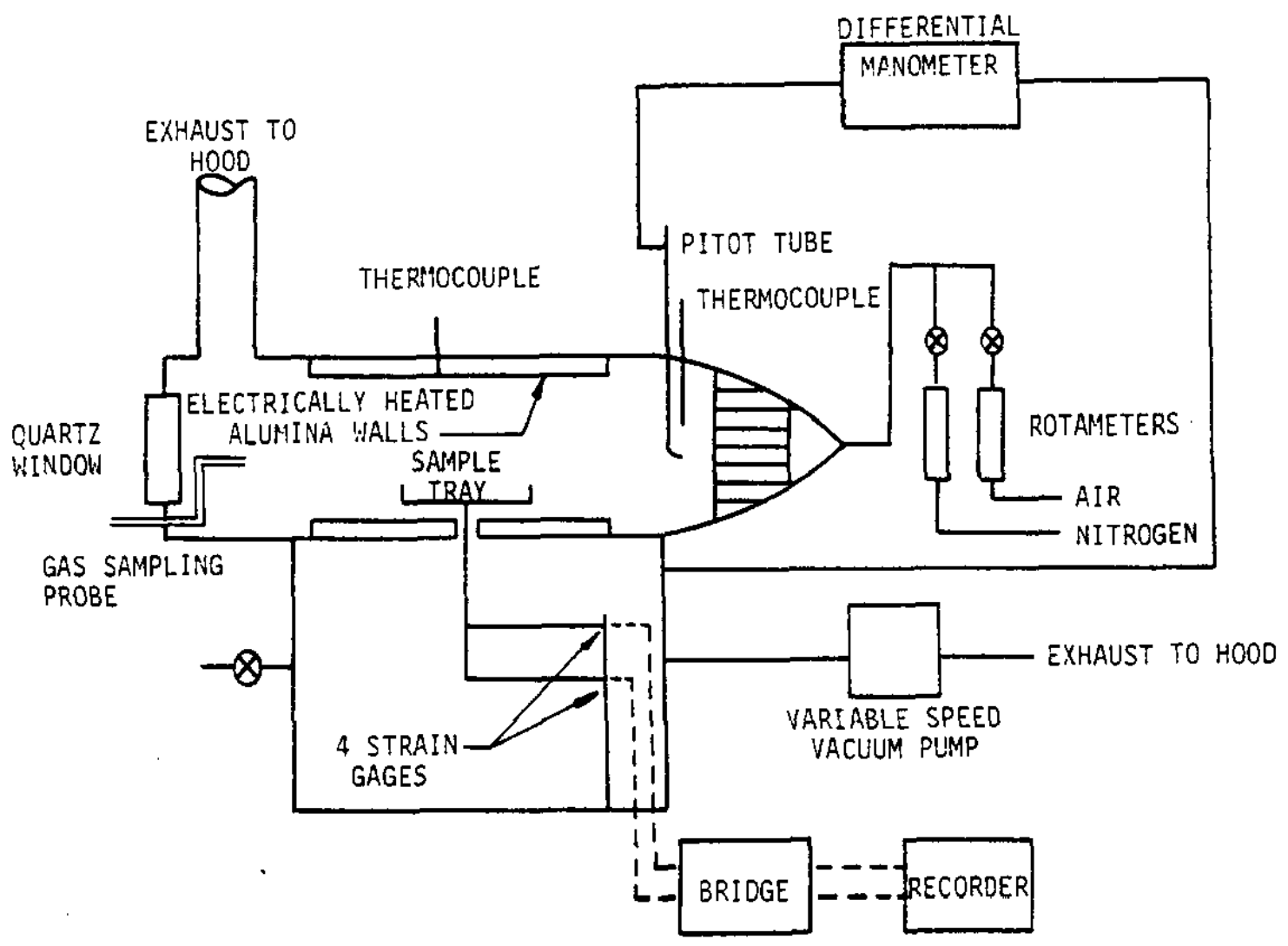

FIGURE 11. Schematic Diagram of Laboratory-Scale Incinerator 
Oxygen concentrations of the inlet gas were controlled at zero or $21 \mathrm{~mol} \%$ by using high pressure cylinders of air and nitrogen. The flow of both air and nitrogen were measured by rotameters. The inlet gas was straightened by an aluminum honeycomb located upstream of the electrically heated section of the incinerator. The temperature of the inlet gas was continuously monitored by a thermocouple located downstream of the honeycomb. Based on the effective diameter of the incinerator, $0.11 \mathrm{~m}$, and an average inlet gas temperature of $100^{\circ} \mathrm{C}$, an upstream Reynolds number, $\mathrm{Re}_{\mathrm{H}}$, range of between 100 and 1000 could be obtained by varying the inlet gas flow rate.

The test unit was equipped with a weighing system which provided continuous polymer sample weight vs. time data during the experiments. The weighing system consisted of a strain gage load cell and four strain gages which were monitored by a bridge and recorder.

The weighing system was connected to a stainless steel platform located inside the electrically heated section of the incinerator. An open ended stainless steel sample tray which contained the polymer sample was placed on top of the steel platform. The pressure difference between the combustion chamber and the weighing chamber (containing the strain gage load cell) was monitored by a capacitance manometer.

The pressure difference between the two chambers was maintained less than $0.03 \mathrm{~mm} \mathrm{Hg}$ by application of a variable speed vacuum pump connected to the lower chamber. This precaution was taken so that leakage into or out of the incinerator from the lower chamber was minimized.

The internal heated section of the incinerator was lined on the top and the two sides by electrically heated alumina plates with a total surface area as seen from the sample of $0.0552 \mathrm{~m}^{2}$. The wall temperature was measured by a platinum vs. platinum $10 \%$ rhodium thermocouple which was in contact with the upper wall surface.

\section{Off-Gas Sampling and Analysis}

Figure 12 shows a schematic of the sampling and analysis system used to measure the off-gas composition from the combustion of polyethylene in the laboratory-scale incinerator. An unquenched sample was taken from the region of the quartz window (Figure 11) through an unheated stainless steel line to the analysis system. Soot and condensible liquids were trapped at the filter so that the analysis could be performed on a dry basis. 


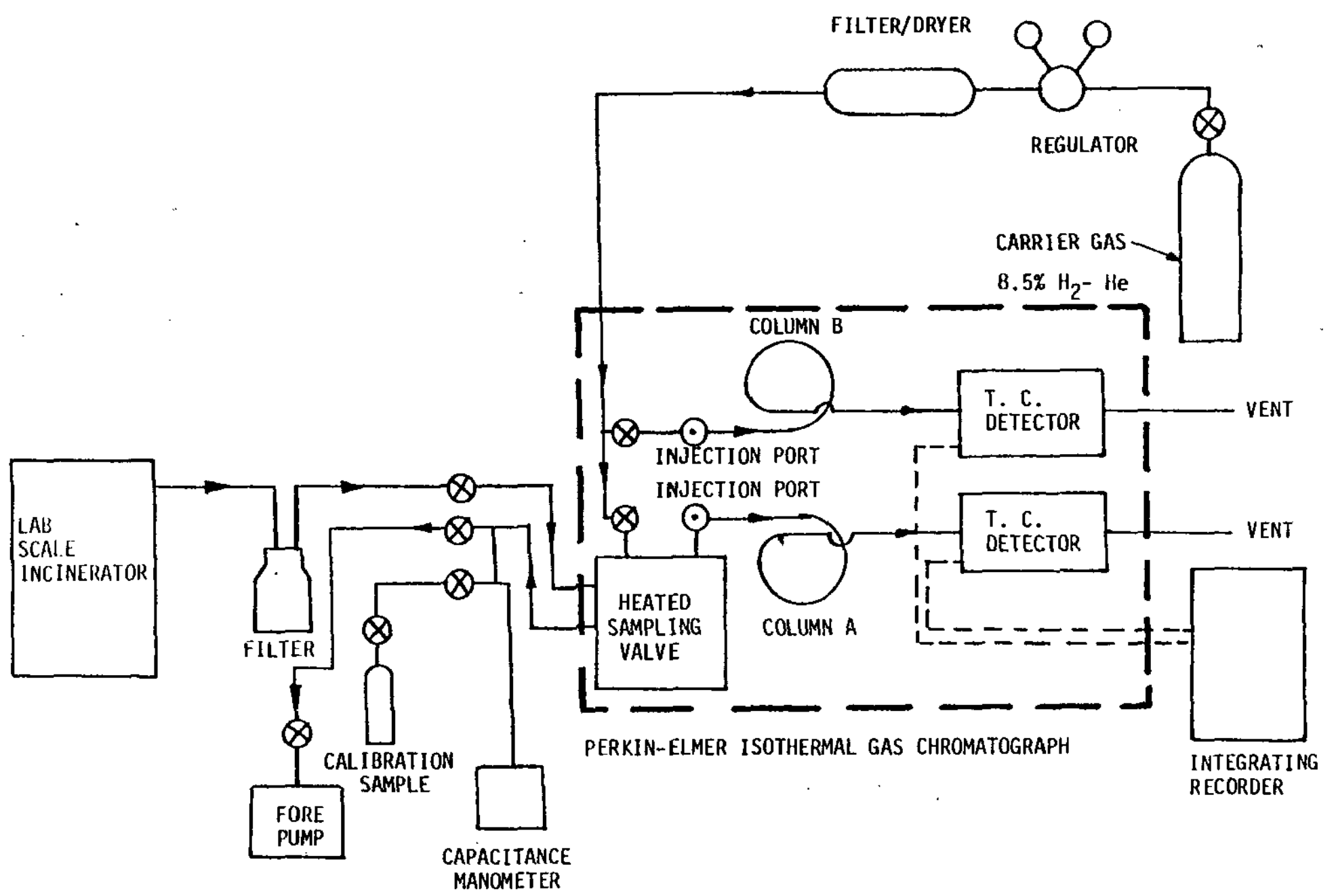

FIGURE 12. Schematic Diagram of Off-Gas Sampling/Analysis System 
As temporal resolved concentration profiles were required, the combustion of large $50-g$ initial sample weights of polyethylene was necessary. Data were obtained at low inlet Reynolds numbers to maximize the relative concentration of each species as compared to nitrogen and to ensure fuel-rich combustion. Two columns were routinely used to separate and quantify the gaseous species. A $60 / 80$ mesh molecular sieve $5 \mathrm{~A}$ stainless steel column was used for $\mathrm{H}_{2}, \mathrm{O}_{2}, \mathrm{~N}_{2}, \mathrm{CH}_{4}$, and $\mathrm{CO}$, and a $80 / 100$ mesh chromasorb-102 stainless steel column was used to measure $\mathrm{CO}_{2}$.

\section{EXPERIMENTAL PROCEDURES}

\section{Pyrolysis and Combustion Rates}

The test unit shown in Figure 11 was used to measure the pyrolysis and combustion rates of $10-\mathrm{g}$ samples of atomic wipes (cellulose), 20-g samples of plastic bags (polyethylene), and $20-g$ samples of rubber gloves (1atex) having initial densities of $60 \mathrm{~kg} / \mathrm{m}^{3}, 516 \mathrm{~kg} / \mathrm{m}^{3}$, and $98 \mathrm{~kg} / \mathrm{m}^{3}$, respectively. The experimental procedures used to measure the pyrolysis and combustion rates are 1 isted below:

1. Preheat furnace wall to desired temperature.

2. Set inlet gas flow composition and Reynolds number.

3. Calibrate weighing system with dead weights.

4. Weigh sample holder by using precision balance.

5. Add known weight of polymer to sample holder.

6. Insert sample on platform in the incinerator and record

a. Strain gage output vs. time

b. Furnace wall temperature vs. time.

7. Remove sample holder with ash and weigh by using precision balance; record ash weight.

8. Calibrate weighing system with dead weights.

Dead weights were used to calibrate the automatic weighing system before and after each experiment. This precaution was taken because the calibration curve shifted as a function of time. Repeated experiments showed that the strain gage output for a particular constant weight varied linearly with time during one experiment. The experiments also showed that the change in output per change in weight was time independent. These facts were used to develop computer software to account for the calibration shift. ${ }^{3}$ Figure 13 shows typical weight vs. time data for the combustion of polyethylene in air. 


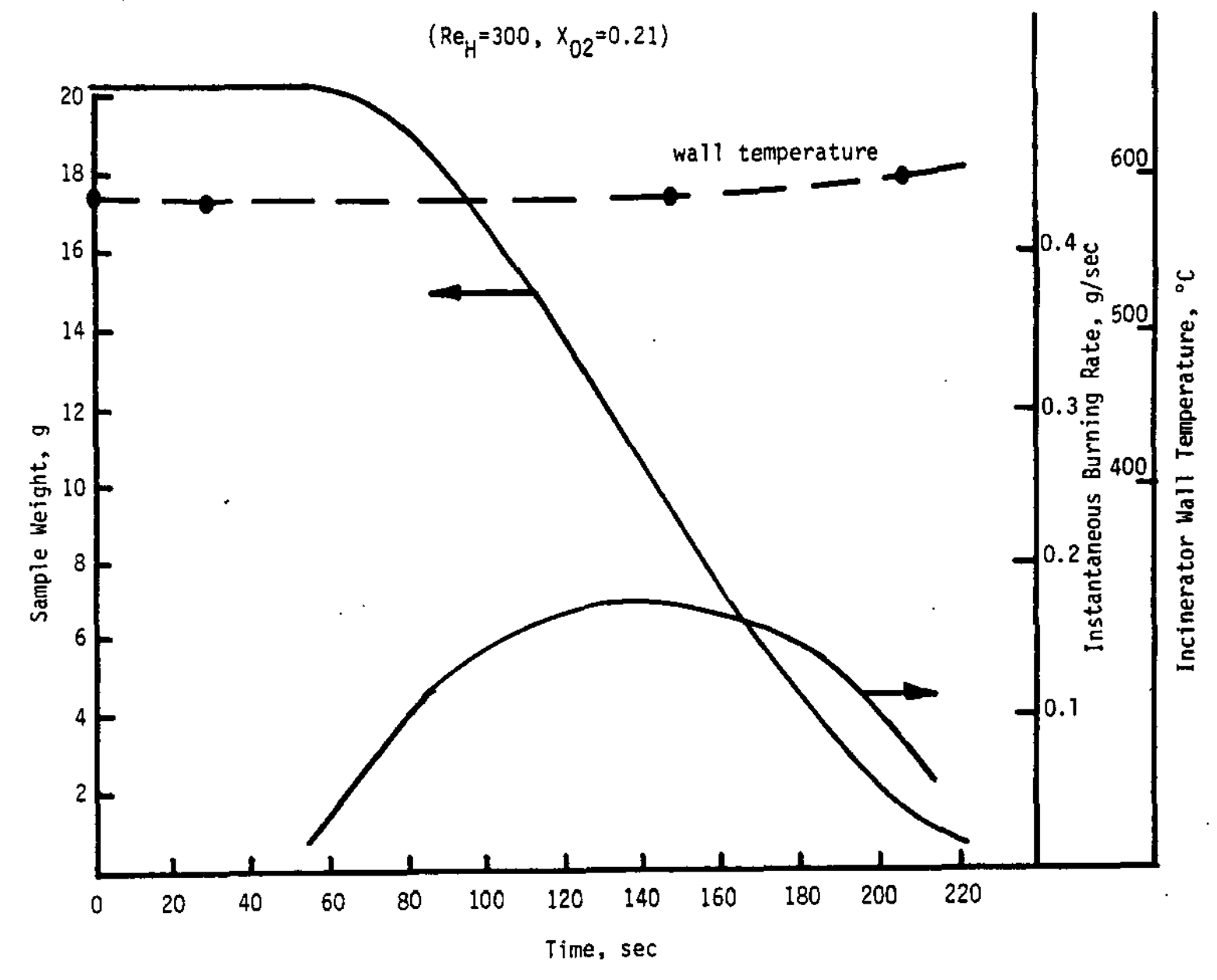

FIGURE 13. Polyethylene Combustion 
Furnace wall temperature, $\mathrm{T}_{\mathrm{w}}$, and instantaneous burning rate are also plotted vs. time. The instantaneous burning rate was determined by numerical differentiation of the weight vs. time curve. An average burning rate was also determined by fitting a straight line by the method of least squares to the weight vs. time data. Data for the average burning rate were taken from the middle $60 \%$ of the weight loss. Rate data reported are the average burning rate unless otherwise specified. Polyethylene typically has a no-weight loss period during which the polymer completely melted prior to ignition. Latex showed partial melting before ignition, and cellulose ignited rapidly after insertion into the experimental incinerator. The average measured burning rates are assumed to represent steady-state burning for the middle of an otherwise transient process. That process includes melting, pyrolysis, ignition, burning at steady state, and extinction (and slow oxidation of remaining char in the case of cellulose).

\section{Off-Gas Sampling and Analysis}

The system shown in Figure 12 was used to measure the partial pressures of several components in the dry off-gas from the laboratory-scale incinerator. The experimental procedure was to identify each effluent species by injecting a pure gas sample into the gas chromatograph. The retention time as recorded on the strip chart recorder was then used to identify that species in subsequent gas mixtures; the mixtures were to be analyzed by the gas chromatograph. A single calibration mixture containing ten percent by volume $\mathrm{CO}, \mathrm{CO}_{2}, \mathrm{H}_{2}$, and $\mathrm{CH}_{4}$ in helium was used at different total pressures between 200 and 1000 torr to obtain peak area vs. species partial pressure. The response was linear for all species calibrated. To test for possible shifts in calibration with time, the gas chromatograph was calibrated before and after each experiment. No calibration shift was observed. In addition to the gas chromatograph, a scanning infrared analyzer was used to identify the components of batch samples when required.

\section{EXPERIMENTAL DATA}

\section{Laboratory-Scale Pyrolysis and Combustion Rates}

Tables 1 through 6 represent the results of experiments in the laboratory-scale incinerator for polyethylene, cellulose, and latex. The tables indicate the composition of the inlet gas to the incinerator (nitrogen or air), the inlet gas Reynolds number $\left(R_{H}\right)$, the initial weight of the sample measured by the precision balance prior to introduction into the incinerator, and the ash weight measured by the precision balance after the sample was removed from the incinerator. The tables also indicate the average rate determined by the procedures described in "Pyrolysis and Combustion Rates," and the incinerator wall temperature, $T_{w}$, measured at fifty percent weight loss. 
TABLE 1

Laboratory-Scale Pyrolysis of Polyethylene (in Mitrogen)

\begin{tabular}{|c|c|c|c|c|}
\hline $\begin{array}{l}\text { Initial } \\
\text { Weight, } \\
\text { g }\end{array}$ & $\mathbf{R e}_{\mathbf{H}}$ & $\begin{array}{l}\mathrm{T} \\
\mathrm{w} \text {, } \\
\end{array}$ & $\begin{array}{l}\text { Ash } \\
\text { We ight, } \\
\text { g }\end{array}$ & $\begin{array}{l}\text { Rate } \\
\mathrm{g} /\left(\mathrm{m}^{2}\right.\end{array}$ \\
\hline 20 & 200 & 542 & 0 & 4.18 \\
\hline 20 & 400 & 538 & 0 & 4.21 \\
\hline 20.4 & 300 & 616 & 0.4 & 11.35 \\
\hline 20.4 & 600 & 603 & 0.4 & 10.70 \\
\hline 20.4 & 300 & 519 & 0.4 & 3.41 \\
\hline 20.3 & 600 & 526 & 0.4 & 4.08 \\
\hline 20.4 & 1000 & 528 & 1.15 & 3.22 \\
\hline 20.2 & 300 & 545 & 0.2 & 5.74 \\
\hline 20.8 & 300 & 505 & 0.9 & 2.73 \\
\hline $2 n .2$ & 300 & 502 & 0.8 & 1.97 \\
\hline 20.3 & 1000 & 539 & 1.0 & 3.30 \\
\hline 20.1 & 300 & 594 & 0.1 & 8.91 \\
\hline
\end{tabular}

TABLE 2

Laboratory-Scale Combustion of Polyethylene (in Air)

\begin{tabular}{|c|c|c|c|c|}
\hline $\begin{array}{l}\text { Initial } \\
\text { Weight, } \\
\text { g }\end{array}$ & ${ }^{R e_{H}}$ & $\begin{array}{l}\mathrm{T} w \\
. \mathrm{c} \\
\end{array}$ & $\begin{array}{l}\text { Ash } \\
\text { Weight, } \\
\text { g }\end{array}$ & $\begin{array}{l}\text { Rate } \\
\mathrm{g} /\left(\mathrm{m}^{2}\right.\end{array}$ \\
\hline 20 & 150 & 604 & 0 & 16.86 \\
\hline 20 & 150 & 583 & 0 & 15.72 \\
\hline 20 & 300 & 587 & 0 & 20.02 \\
\hline 20 & 600 & 589 & 0 & 15.38 \\
\hline 20 & 900 & 593 & 0 & 21.28 \\
\hline 20 & 150 & 530 & 0 & 11.28 \\
\hline 20 & 150 & 530 & 0 & 11.39 \\
\hline 20 & 300 & 520 & 0 & 11.25 \\
\hline 20 & 150 & 502 & 0 & 9.97 \\
\hline 20 & 600 & 537 & 0 & 13.25 \\
\hline 19.8 & 300 & 532 & 0 & 11.74 \\
\hline 20.2 & 150 & 503 & 0.1 & 5.41 \\
\hline 20.1 & 600 & 507 & 0.1 & 12.97 \\
\hline 20.1 & 150 & 483 & 0.1 & 5.06 \\
\hline 20.1 & 300 & 567 & 0.1 & 16.38 \\
\hline 20.1 & 300 & 511 & 0.1 & 15.40 \\
\hline 20.2 & 300 & 484 & 0 & 9.41 \\
\hline 20 & 300 & 608 & 0 & 17.61 \\
\hline
\end{tabular}


TABLE 3

Laboratory-Scale Pyrolysis of Cellulose (in Nitrogen)

\begin{tabular}{|c|c|c|c|c|c|}
\hline $\begin{array}{l}\text { Initial } \\
\text { Weight, } \\
\text { g } \\
\end{array}$ & $\mathrm{Re}_{\mathrm{H}}$ & $\begin{array}{l}\mathrm{T}_{\mathrm{w}}, \\
\stackrel{\mathrm{C}}{\mathrm{C}}, \\
\end{array}$ & $\begin{array}{l}\text { Ash } \\
\text { Weight, } \\
\text { g }\end{array}$ & $\begin{array}{l}\text { Rate }{ }_{2} \\
\mathrm{~g} /\left(\mathrm{m}^{2}\right. \\
\end{array}$ & sec) \\
\hline 11.55 & 300 & 560 & 0.9 & 5.54 & \\
\hline 10.30 & 300 & 550 & 0.6 & 6.11 & \\
\hline 10.60 & 600 & 540 & 1.0 & 5.22 & \\
\hline 10.20 & 1000 & 525 & 0 & 5.82 & \\
\hline 10.50 & 200 & 387 & 1.9 & 3.31 & \\
\hline 11.1 & 400 & 381 & 2.8 & 2.35 & \\
\hline 10.7 & 300 & 448 & 1.7 & 2.16 & \\
\hline 11.3 & 300 & 523 & 1.0 & 6.47 & \\
\hline 9.8 & 300 & 556 & 0.6 & 5.44 & \\
\hline
\end{tabular}

TABLE 4

Laboratory-Scale Combustion of Cellulose (in Air)

\begin{tabular}{|c|c|c|c|c|}
\hline $\begin{array}{l}\text { Initial } \\
\text { Weight, } \\
\text { g }\end{array}$ & $\mathrm{Re}_{\mathrm{H}}$ & $\begin{array}{l}\mathrm{T}_{\mathrm{w}} \\
{ }^{\circ} \mathrm{C} \\
\end{array}$ & $\begin{array}{l}\text { Ash } \\
\text { Weight, } \\
\text { g }\end{array}$ & $\begin{array}{l}\text { Rate } \\
\mathrm{g} /\left(\mathrm{m}^{2}\right.\end{array}$ \\
\hline 11.55 & 300 & 580 & 0.45 & 9.88 \\
\hline 11.6 & 300 & 571 & 0.45 & 9.93 \\
\hline 12.0 & 600 & 540 & 0.45 & 9.89 \\
\hline 10.7 & 150 & 550 & 0.3 & 9.36 \\
\hline 10.2 & 300 & 550 & 0 & 9.99 \\
\hline 10.0 & 600 & 550 & 0.2 & 10.76 \\
\hline 10.1 & 900 & 535 & 0 & 9.51 \\
\hline 11.1 & 300 & 483 & 0.3 & 7.34 \\
\hline 11.2 & 300 & 580 & 0.1 & 8.18 \\
\hline 9.4 & 300 & 579 & 0.1 & 10.58 \\
\hline
\end{tabular}


TABLE 5

Laboratory-Scale Pyrolysis of Latex (in Nitrogen)

$\mathrm{Re}_{\mathbf{H}}=\mathbf{3 0 0}$

\begin{tabular}{|c|c|c|c|}
\hline $\begin{array}{l}\text { Initial } \\
\text { Weight, } \\
\text { g }\end{array}$ & $\begin{array}{l}\mathrm{T}_{\mathrm{W}}, \\
\stackrel{\circ}{\mathrm{C}} \\
\end{array}$ & $\begin{array}{l}\text { Ash } \\
\text { Weight, } \\
\text { g } \\
\end{array}$ & $\begin{array}{l}\text { Rate, } \\
g /\left(\mathrm{m}^{2} \mathrm{sec}\right)\end{array}$ \\
\hline 20.3 & 401 & 2.0 & 4.51 \\
\hline 20.4 & 407 & 0.4 & 5.87 \\
\hline 20.4 & 446 & 0.4 & 9.20 \\
\hline 20.4 & 468 & 0.5 & 11.27 \\
\hline 20.3 & 502 & 0.3 & 11.86 \\
\hline 20.3 & 453 & 0.4 & 12.06 \\
\hline 20.4 & 493 & 0.5 & 15.98 \\
\hline 20.3 & 495 & 0.4 & 16.96 \\
\hline 20.35 & 503 & 0.3 & 16.86 \\
\hline 20.4 & 543 & 0.4 & 22.16 \\
\hline 20 & 534 & 0.35 & 30.29 \\
\hline 20 & 533 & 0.4 & 29.02 \\
\hline 20.3 & 519 & 0.2 & 35.10 \\
\hline
\end{tabular}

\section{TABLE 6}

\begin{tabular}{|c|c|c|c|}
\hline $\begin{array}{l}\text { Initial } \\
\text { Weight, } \\
\text { g }\end{array}$ & $\begin{array}{l}{ }_{\mathrm{T}} \mathrm{W}, \\
{ }^{\circ} \mathrm{C} \\
\end{array}$ & $\begin{array}{l}\text { Ash } \\
\text { Weight, } \\
\text { g }\end{array}$ & $\begin{array}{l}\text { Rate, } \\
\mathrm{g} /\left(\mathrm{m}^{2} \mathrm{sec}\right)\end{array}$ \\
\hline 20.3 & 456 & 0.4 & 14.61 \\
\hline 20.4 & 440 & 0.4 & 18.92 \\
\hline 20.3 & 455 & 0.3 & 13.10 \\
\hline 20.4 & 565 & 0.2 & 19.30 \\
\hline 20.4 & 548 & 0.2 & 25.78 \\
\hline 20.5 & 530 & 0.3 & 23.53 \\
\hline 19.6 & 530 & 0.4 & 24.51 \\
\hline 19.6 & 520 & 0.4 & 33.04 \\
\hline 19.2 & 487 & 0.2 & 5.78 \\
\hline
\end{tabular}




\section{ICTF Combustion Rates}

Tables 7 through 9 represent the results of burning rate experiments performed by SRL personnel on the ICTF. In these experiments, the cylindrical primary of the ICTF was loaded with single packages of polyethylene, cellulose, or latex enclosed in paper bags. The dimensions of the bags and primary chambers are shown in each table. In all cases, the primary air was maintained at $12 \mathrm{cfm}$ with no steam addition. The burning time was measured by recording the time from ignition to extinction as observed visually through a site glass in the ICTF primary. The average combustion rate was determined by dividing the initial sample weight by the burning time.

\section{ANALYTICAL MODELS}

Two interdependent models are developed in this section: a phenomenological model and a mass burning rate model. The phenomenological model of polymer pyrolysis is used in the absence of oxygen. This model, along with the experimental results, may be used to deduce an effective heat of gasification and characteristic polymer surface temperature. These results were used in a mass burning rate model to predict burning rate as a function of incinerator wall temperature.

\section{Pyrolysis Rate}

Although a kinetic model, as described in the earlier work ${ }^{2}$ on Teflon (Du Pont Co.), could be extended to several polymers, this approach was abandoned in favor of a phenomenological approach. Review of pyrolysis literature, ${ }^{4-5}$ indicated that some polymers have been found to degrade at a constant rate proportional to the radiant heat flux incident on the polymer surface. Early pyrolysis experiments ${ }^{6-7}$ on porous samples of materials discussed in this report also showed this relationship. Recent experimental work at Factory Mutual Research ${ }^{8-12}$ has indicated that the concept of an effective heat of gasification, $\mathrm{L}_{\mathrm{g}}$, and characteristic polymer surface temperature, $\mathrm{T}_{\mathrm{s}}$, during thermal degradation may be used for melting and charring polymers. These assumptions are valid as long as the phenomena under study are of a quasi-steady nature. 13 
TABLE 7

ICTF No-Steam Experimental Combustion Rate Data

Cellulose - Air (12 cfm)

Primarv

Initial $\overline{\mathrm{d}}_{1}, \quad \overline{\mathrm{d}}_{2}, \quad \mathrm{~L}, \quad \begin{aligned} & \text { Burn } \\ & \text { Time, Rate, }\end{aligned}$

$\begin{array}{lllllll}\text { Temp., Initial } & \overline{\mathrm{d}}_{1}, & \overline{\mathrm{d}}_{2}, & \mathrm{~L}, & \text { Time, } & \text { Rate, } \\ { }^{\circ} \mathrm{C} & \text { Wt., } \mathrm{g} & \text { inch } & \text { inch } & \text { inch } & \mathrm{sec} & \mathrm{g} / \mathrm{sec}\end{array}$

$\begin{array}{lllllll}500 & 200 & 3.0 & 4.0 & 8.0 & 838 & 0.24 \\ 500 & 200 & 3.5 & 4.5 & 7.5 & 652 & 0.31 \\ 600 & 200 & 3.5 & 4.5 & 7.5 & 765 & 0.26 \\ 600 & 200 & 3.5 & 4.5 & 7.5 & 660 & 0.30 \\ 700 & 200 & 3.5 & 4.5 & 8.0 & 581 & 0.34 \\ 700 & 200 & 3.5 & 4.5 & 9.0 & 345 & 0.58 \\ 800 & 200 & 3.5 & 4.5 & 7.5 & 447 & 0.45 \\ 900 & 200 & 3.5 & 4.5 & 8.0 & 216 & 0.92 \\ 800 & 200 & 3.0 & 3.75 & 8.0 & 477 & 0.42 \\ 900 & 200 & 3.5 & 4.5 & 7.0 & 420 & 0.48 \\ 800 & 200 & 3.5 & 3.5 & 7.5 & 600 & 0.33 \\ 900 & 200 & 3.0 & 3.5 & 8.25 & 448 & 0.45 \\ 900 & 200 & 3.0 & 3.75 & 8.0 & 498 & 0.40\end{array}$

Rate $=\frac{\text { Initial Weight }}{\text { Burn Time }}$

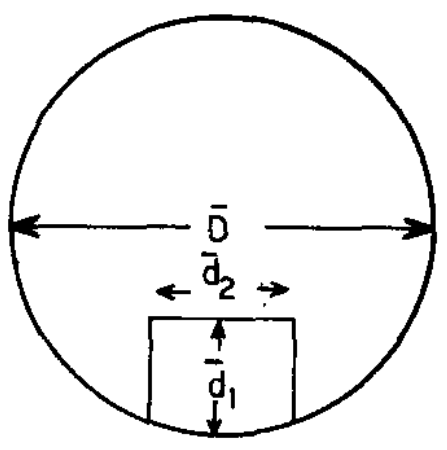

TYPICAL VALUES

$\mathrm{L}=$ sample length $\simeq 0.1968 \mathrm{~m}$

$\overline{\mathrm{d}}_{2}=$ sample width $\simeq 0.1143 \mathrm{~m}$

$\bar{d}_{1}=$ sample height $\simeq 0.0889 \mathrm{~m}$

$\overline{\mathrm{D}}=$ primary chamber diameter

$=0.2160 \mathrm{~m}$ 


\section{TABLE 8}

ICrF No-Steam Experimental Combustion Rate Data

\begin{tabular}{|c|c|c|c|c|c|}
\hline $\begin{array}{l}\text { Primary } \\
\text { Temp., } \\
{ }^{\circ} \mathrm{C} \\
\end{array}$ & $\begin{array}{l}\text { Initial } \\
\text { Wt, g }\end{array}$ & $\begin{array}{l}\bar{d} \\
\text { Dia., } \\
\text { inch }\end{array}$ & $\begin{array}{l}\text { L, } \\
\text { Length, } \\
\text { inch }\end{array}$ & $\begin{array}{l}\text { Burn } \\
\text { Time, } \\
\text { sec }\end{array}$ & $\begin{array}{l}\text { Rate, } \\
\text { g/sec }\end{array}$ \\
\hline 500 & 200 & 2.0 & 10.5 & 805 & 0.25 \\
\hline 600 & 200 & 2.5 & 10.0 & 705 & 0.28 \\
\hline 600 & 200 & 2.25 & 11.0 & 405 & 0.49 \\
\hline 700 & 100 & 3.0 & 6.5 & 255 & 0.39 \\
\hline 700 & 100 & 2.25 & 7.0 & 280 & 0.36 \\
\hline 700 & 200 & 3.0 & 10.5 & 341 & 0.59 \\
\hline 800 & 100 & 2.25 & 6.0 & 157 & 0.64 \\
\hline 800 & 100 & 2.0 & 6.5 & 173 & 0.58 \\
\hline 900 & 100 & 2.0 & 6.5 & 153 & 0.65 \\
\hline 900 & 100 & 2.5 & 6.75 & 135 & 0.74 \\
\hline 500 & 200 & 2.5 & 10.0 & 465 & 0.42 \\
\hline
\end{tabular}

Rate $=\frac{\text { Initial Weight }}{\text { Burn Time }}$

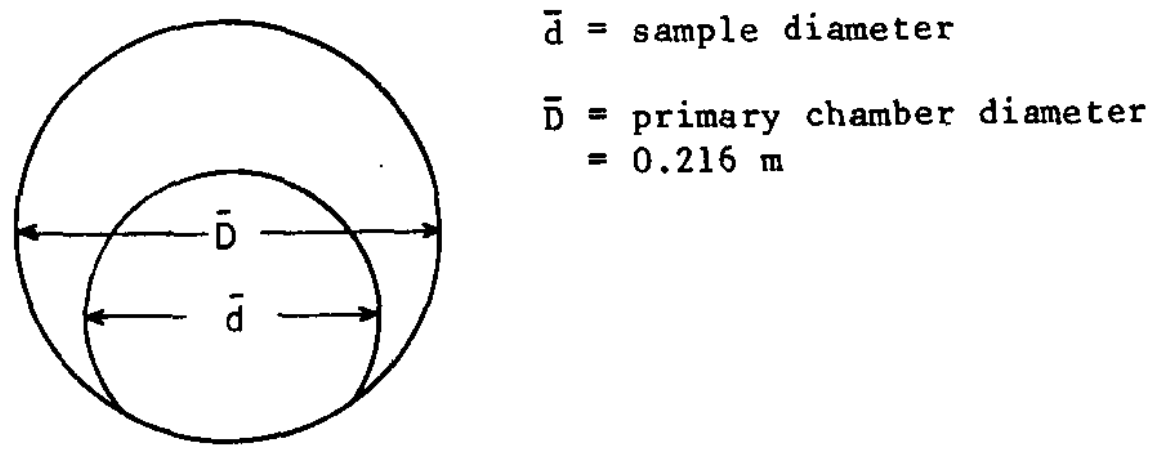


TABLE 8 (Continued)

ICTF No-Steam Experimental Combustion Rate Data

Polyethylene - Air

\begin{tabular}{|c|c|c|c|c|c|}
\hline $\begin{array}{l}\text { Primary } \\
\text { Temp., } \\
{ }^{\circ} \mathrm{C} \\
\end{array}$ & $\begin{array}{l}\text { Initial } \\
\text { Wt..g }\end{array}$ & $\begin{array}{l}\overline{\mathrm{d}} \\
\text { nia., } \\
\text { inch } \\
\end{array}$ & $\begin{array}{l}\text { L, } \\
\text { Length, } \\
\text { inch } \\
\end{array}$ & $\begin{array}{l}\text { Burn } \\
\text { Time, } \\
\text { sec } \\
\end{array}$ & $\begin{array}{l}\text { Rate, } \\
\text { g/sec }\end{array}$ \\
\hline 500 & 100 & 1.75 & 10.5 & 352 & 0.28 \\
\hline 500 & 100 & 1.75 & 10.0 & 341 & 0.29 \\
\hline 600 & 100 & 1.50 & 10.0 & 246 & 0.41 \\
\hline 600 & 100 & 1.75 & 10.0 & 225 & 0.44 \\
\hline 700 & 100 & 1.50 & 10.0 & 251 & 0.40 \\
\hline 700 & 100 & 1.75 & 10.5 & 220 & 0.45 \\
\hline 800 & 100 & 1.75 & 9.5 & 160 & 0.62 \\
\hline 800 & 100 & 1.50 & 10.0 & 174 & 0.57 \\
\hline 900 & 100 & 1.75 & 10.0 & 114 & 0.88 \\
\hline 900 & 100 & 1.75 & 9.5 & 140 & 0.71 \\
\hline
\end{tabular}

Rate $=\frac{\text { Initial Weight }}{\text { Burn Time }}$

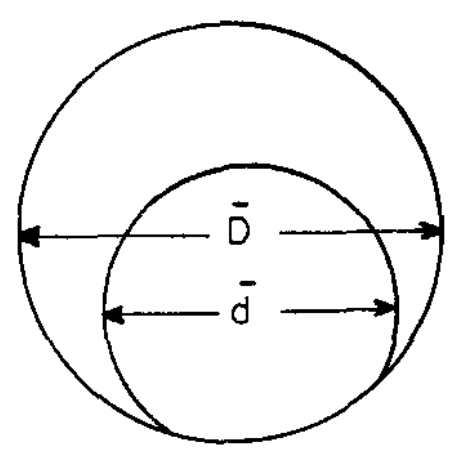


TABLE 9

ICTF No-Steam Experimental Combustion Rate Data

\begin{tabular}{|c|c|c|c|c|c|}
\hline $\begin{array}{l}\text { Primary } \\
\text { Temp., } \\
{ }^{\circ} \mathrm{C} \\
\end{array}$ & $\begin{array}{l}\text { Initial } \\
\text { Wt., g } \\
\end{array}$ & $\begin{array}{l}\mathrm{d} \\
\text { Dia., } \\
\text { inch } \\
\end{array}$ & $\begin{array}{l}\text { L, } \\
\text { Length, } \\
\text { inch } \\
\end{array}$ & $\begin{array}{l}\text { Burn } \\
\text { Time, } \\
\text { sec }\end{array}$ & $\begin{array}{l}\text { Rate, } \\
\text { g/sec }\end{array}$ \\
\hline 500 & 100 & 2.25 & 6.0 & 162 & 0.62 \\
\hline 500 & 100 & 1.50 & 6.75 & 162 & 0.62 \\
\hline 600 & 100 & 1.25 & 7.5 & 127 & 0.79 \\
\hline 600 & 100 & 1.50 & 6.0 & 123 & 0.81 \\
\hline 700 & 100 & 1.50 & 7.0 & 79 & 1.26 \\
\hline 700 & 100 & 1.50 & 6.0 & 79 & 1.26 \\
\hline 800 & 100 & 2.0 & 5.0 & 65 & 1.54 \\
\hline 800 & 100 & 1.75 & 5.25 & 110 & 0.91 \\
\hline 900 & 100 & 1.75 & 5.50 & 60 & 1.67 \\
\hline 900 & 100 & 1.75 & 5.0 & 55 & 1.82 \\
\hline
\end{tabular}

Rate $=\frac{\text { Initial Weight }}{\text { Burn Time }}$

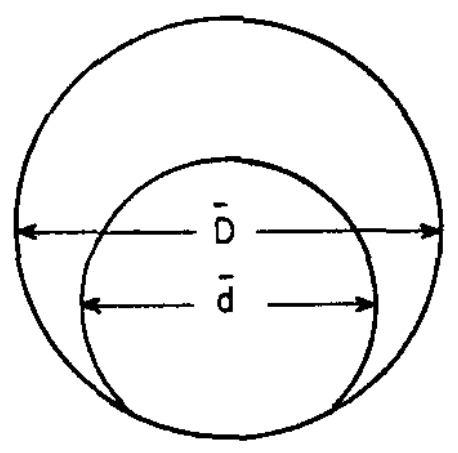

TYPICAL VALUES

$\mathrm{L}=0.1524 \mathrm{~m}$

$\overline{\mathrm{d}}=0.0425 \mathrm{~m}$

$\overline{\mathrm{D}}=0.2160 \mathrm{~m}$ 
If the net heat flux to the charring polymer surface is assumed to be uniform (Figure 14), the pyrolysis is steady, and the nonreacting char residue is at a uniform temperature, $\mathrm{T}_{\mathbf{s}}$

$$
\begin{aligned}
q_{n e t}= & r\left(\rho_{o}-\rho_{c}\right)\left\lfloor C_{p p}\left(T_{p}-T_{\infty}\right)+L_{s}\right\rfloor+ \\
& \quad r p c_{p c}\left(T_{s}-T_{\infty}\right)
\end{aligned}
$$

It will be assumed that heat transfer within the porous char is rapid; therefore

$$
\mathrm{T}_{\mathrm{p}} \simeq \mathrm{T}_{\mathrm{s}}
$$

The net heat flux to the polymer surface is

$$
q_{\text {net }}=\sigma F_{w s} \frac{A_{w}}{A_{s}}\left(T_{w}^{4}-T_{s}^{4}\right)+h\left(T_{\delta}-T_{s}\right)
$$

where $h$ is the heat transfer coefficient for combined forced and free convection over the polymer surface. For the experiments reported, the second term in Equation 3 may be neglected in comparison to the first term. Combining the above equations and rearranging yields

$$
\begin{aligned}
& \frac{\sigma \mathrm{F}_{\mathrm{ws}} \frac{\mathrm{A}_{\mathrm{w}}}{\mathrm{A}_{\mathrm{s}}}\left(\mathrm{T}_{\mathrm{w}}^{4}-\mathrm{T}_{\mathrm{s}}^{4}\right)}{\left(\rho_{0}-\rho_{c}\right) \mathrm{r}}=\left[\mathrm{C}_{\mathrm{pp}}\left(\mathrm{T}_{\mathrm{s}}-\mathrm{T}_{\infty}\right)+\mathrm{L}_{\mathrm{s}}\right]+ \\
& \left(\frac{\rho_{c}}{\rho_{0}-\rho_{\mathrm{c}}}\right) \mathrm{C}_{\mathrm{pc}}\left(\mathrm{T}_{\mathrm{s}}-\mathrm{T}_{\infty}\right)
\end{aligned}
$$

Using continuity at the polymer char surface, the pyrolysis rate is given by

$$
\dot{m}_{p}=r A_{s}\left(\dot{\rho}_{o}-\rho_{c}\right)
$$




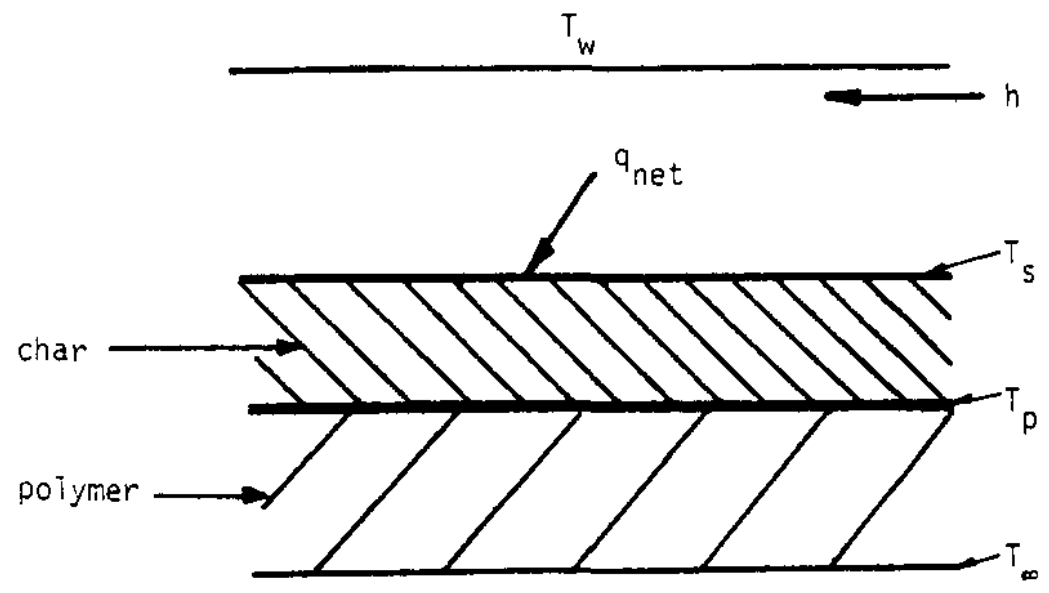

FIGURE 14. Schematic of Pyrolysis Process for a Charring Polymer 
Combining Equations 4 and 5 yields

$$
\dot{m}^{\prime \prime}=\frac{\dot{m}_{p}}{A_{s}}=\frac{\sigma F_{w s} \frac{A_{w}}{A_{s}}\left(T_{w}{ }^{4}-T_{s}{ }^{4}\right)}{\left\lfloor C_{p p}\left(T_{s}-T_{\infty}\right)+L_{s}\right\rfloor+\left(\frac{\rho_{c}}{\rho_{0}-\rho_{c}}\right) C_{p c}\left(T_{s}-T_{\infty}\right)}
$$

For the case of a charring polymer, cellulose, the denominator of Equation 6 is a material property defined as the effective heat of gasification

$$
I_{g}=\left\lfloor C_{p p}\left(T_{s}-T_{\infty}\right)+L_{s}\right\rfloor+\frac{\rho_{c}}{\rho_{o}-\rho_{c}} C_{p c}\left(T_{s}-T_{\infty}\right)
$$

For the case of a melting noncharring polymer, polyethylene, or latex, the denominator of Equation 6 is again a material property defined as the effective heat of gasification, where $\rho_{c}$ is zero by definition. Equation 7 is then

$$
\mathrm{L}_{g}=\mathrm{C}_{\mathrm{pp}}\left(\mathrm{T}_{s}-\mathrm{T}_{\infty}\right)+\mathrm{L}_{s}
$$

Combining Equation 7 or 8 with Equation 6 yields

$$
\dot{\mathrm{w}}^{\prime \prime}=\frac{\dot{\mathrm{m}}_{\mathrm{p}}}{\mathrm{A}_{\mathrm{s}}}=\frac{\sigma \mathrm{F}_{\mathrm{ws}} \frac{\mathrm{A}_{\mathrm{w}}}{\mathrm{A}_{\mathrm{s}}}\left(\mathrm{T}_{\mathrm{w}}^{4}-\mathrm{T}_{\mathrm{s}}^{4}\right)}{\mathrm{L}_{\mathrm{g}}}
$$

Implied in this phenomenological approach is the approximation that independent of the heat flux to the polymer surface, the characteristic surface temperature remains fixed at $T_{8}$.

\section{Combustion Rate}

The mass burning model, which is developed, assumes that the rate of combustion is steady and that the chemical reaction rate of the diffusion flame above the burning polymer is fast compared to the diffusion of oxygen into the flame front. 
Figure 15 shows a schematic of the incinerator and defines the dimensional constants to be user in the analytical model. Glassman ${ }^{14}$ has derived the following mass burning model under conditions of no external radiation.

$$
\dot{\mathrm{m}}^{\prime \prime}=\left(\frac{\rho N}{\delta}\right) \ln (1+B)
$$

The mass transfer number, $R$, may be conveniently defined as,

$$
B=\frac{i\left(M_{O_{2}}\right)_{\delta} \Delta H_{c}+c_{p}\left(T_{\delta}-T_{s}\right)}{L_{g}}
$$

where the mass stoichiometric index, $i$, is defined by the single step stoichiometric relation ${ }^{15}$

$$
\begin{aligned}
& i \text { g of fuel }+1 g \text { of oxygen } \rightarrow(1+i) g \text { of } \\
& \text { product }\left(\mathrm{CO}_{2}+\mathrm{H}_{2} \mathrm{O}\right)
\end{aligned}
$$

In the gas phase, it may be assumed that the Lewis number is unity.

$$
\mathrm{L}_{\mathrm{e}}=\frac{\alpha}{\mathrm{D}}=1
$$

Then

$$
\alpha=D
$$

where by definition

$$
\alpha=\frac{k}{\rho C_{p}}
$$

Therefore

$$
\rho \alpha=\rho D=\frac{K}{C_{p}}
$$




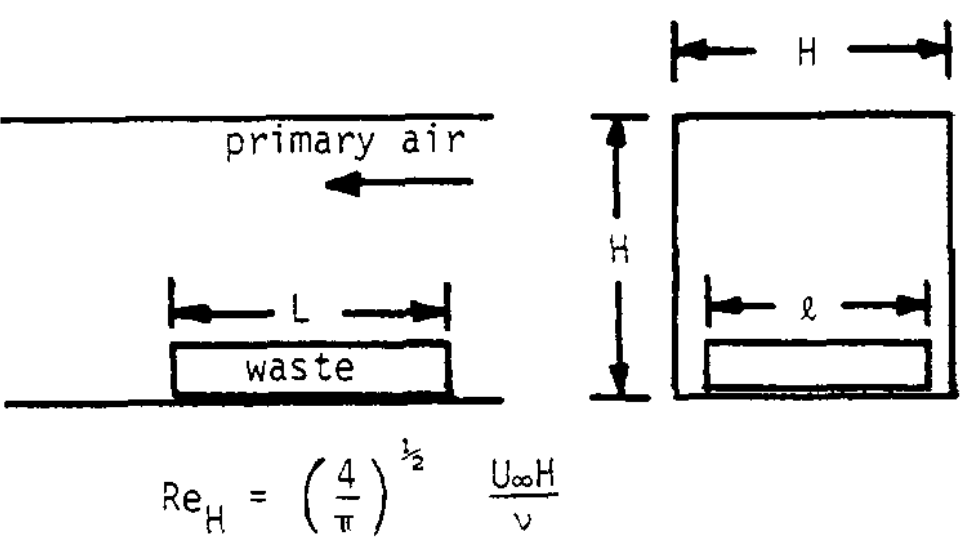

FIGURE 15. Schematic of the Laboratory-Scale Incinerator 
Equation 16 with Equation 10 yields

$$
\dot{\mathrm{m}}^{\prime \prime}=\frac{\mathrm{K}}{\delta \mathrm{C}_{\mathrm{p}}} \ln (1+\mathrm{B})
$$

For the case of an externally applied heat flux, Equation 17 may be modified $14,16-18$ as

$$
\dot{\mathrm{m}}^{\prime \prime}=\frac{\mathrm{K}}{\delta \mathrm{C}_{\mathrm{p}}} \ln \left\{1+\frac{\mathrm{B}}{1-\mathrm{E}}\right\}
$$

The radiation heat transfer parameter $E$ is defined in terms of the net radiation heat flux $Q_{R}$ to the polymer surface.

$$
E=\frac{\dot{Q}_{R}}{\dot{\mathrm{m}}^{\prime \prime} \mathrm{L}_{\mathrm{g}}}
$$

where

$$
\dot{\mathrm{Q}}_{\mathrm{R}}=\dot{\mathrm{Q}}_{\mathrm{RF}}+\dot{\mathrm{Q}}_{\mathrm{E}}-\dot{\mathrm{Q}}_{\mathrm{L}}
$$

In studies $15,17-21$ of polymer combustion, radiation from the flame to the polymer surface has been considered. Some authors 14,22 have argued that in some cases, flame radiation may be neglected. In the present experiment, a large portion of the flame radiation will be incident upon the incinerator walls, and will be absorbed and re-emitted by those walls at the measured wall temperature $T_{w}$. Therefore, most of the flame radiation is already accounted for in the external radiation term $Q_{E}$. The state of the art, in predicting flame radiation, requires knowledge of soot concentration and combustion product concentrations. 23,24 These data, for the present experiments, are unavailable; therefore, the radiant heat flux from the flame to the polymer surface $Q_{R F}$ will be neglected in the analysis.

$$
Q_{R F} \simeq 0(\text { neglected })
$$


Combining Equations 19, 20, and 21 yields

$$
E=\frac{\dot{\mathrm{o}}_{\mathrm{E}}-\dot{\mathrm{n}}_{\mathrm{L}}}{\dot{\mathrm{m}}^{\prime \prime} \mathrm{L}_{\mathrm{g}}}
$$

Earlier work on the pyrolysis of porous samples of Teflon ${ }^{2}$ in a similar furnace geometry has shown that the numerator of Equation 22 may be expressed as

$$
\dot{\mathrm{Q}}_{\mathrm{E}}-\dot{\mathrm{O}}_{\mathrm{L}}=\sigma \mathrm{F}_{\mathrm{wS}} \frac{\mathrm{A}_{\mathrm{w}}}{\mathrm{A}_{\mathrm{s}}}\left(\mathrm{T}_{\mathrm{w}}^{4}-\mathrm{T}_{\mathrm{s}}^{4}\right)
$$

where

$$
F_{w s}=\left[\frac{1}{\varepsilon_{w}}-1+\frac{A_{w}}{A_{S}}\left(\frac{1}{\varepsilon_{s}}\right)\right]^{-1}
$$

Based on radiation absorption measurements for various polymers ${ }^{25}$ and Kirchhoff's identity

$$
\varepsilon_{s} \simeq 1
$$

Using Equations 24 and 25 and the following datal on the laboratory-scale incinerator, the angle factor was calculated to be

$$
\mathrm{F}_{\mathrm{wS}}=0.137
$$

where

$$
\begin{aligned}
& A_{w}=0.0552 \mathrm{~m}^{2} \\
& A_{s}=0.0102 \mathrm{~m}^{2} \\
& \varepsilon_{w}=0.55
\end{aligned}
$$

Combining Equations $11,18,22$, and 23 yields the following mas burning equation 


$$
\dot{m}^{\prime \prime}=\left(\frac{\mathrm{K}}{\delta \mathrm{C}_{\mathrm{p}}}\right) \ln \left\{\frac{1+i\left(\mathrm{M}_{\mathrm{O}_{2}}\right)_{\delta} \Delta \mathrm{H}_{\mathrm{c}}+\mathrm{C}_{\mathrm{p}}\left(\mathrm{T}_{\delta}-\mathrm{T}_{\mathrm{s}}\right)}{\left[\mathrm{L}_{\mathrm{g}}-\left(\frac{\sigma \mathrm{F}_{\mathrm{ws}}\left(\mathrm{A}_{\mathrm{w}} / \mathrm{A}_{\mathrm{s}}\right)\left(\mathrm{T}_{\mathrm{w}}^{4}-\mathrm{T}_{s}{ }^{4}\right)}{\dot{\mathrm{m}}^{\prime \prime}}\right)\right]}\right\}
$$

In the present experimental test unit, experiments with an oxygen mass fraction of zero indicated that the primary air is preheated to a temperature just slightly less than the incinerator wall temperature by the time it reaches the heated section of the furnace. Therefore

$$
T_{\delta} \simeq T_{w}
$$

also

$$
\left(\mathrm{M}_{2}\right)_{\delta} \simeq\left(\mathrm{M}_{\mathrm{O}_{2}}\right)_{\infty}
$$

Equation 27 may be used to predict mass burning rates if the term $\mathrm{K} / \delta \mathrm{C}_{\mathrm{p}}$ can be evaluated. For the case of combined free and forced convection in a horizontal tube, Holman ${ }^{26}$ suggests the following criteria for determining if free convection dominates.

$$
\text { If } \frac{\mathrm{Gr}_{\mathrm{f}}}{\operatorname{Re}_{\mathrm{L}}^{2}}>1 \text { (then free convection dominates) }
$$

where $\operatorname{Re}_{\mathrm{L}}=\frac{\rho_{\mathrm{f}} \mathrm{U}_{\infty} \mathrm{L}}{\mu_{\mathrm{f}}}$ and $\operatorname{Re}_{\mathrm{L}}=\frac{\rho_{\mathrm{f}} \nu}{\mu_{\mathrm{f}}}\left(\frac{\mathrm{L}}{\mathrm{H}}\right)\left(\frac{\pi}{4}\right)^{1 / 2} \operatorname{Re}_{\mathrm{H}}$

and where the density and viscosity are taken as those of the inlet gas evaluated at the film temperature, $\mathrm{T}_{\mathbf{f i l m}}$.

$$
\mathrm{T}_{\mathrm{film}}=\frac{\mathrm{T}_{\mathrm{fl}}+\mathrm{T}_{\mathrm{s}}}{2}
$$

The Grashof number is also evaluated by using the gas properties as described above. The Grashof number is defined ${ }^{26}$ as 


$$
G r_{f}=\frac{g d^{3} \beta \Delta T f_{f}^{2}}{\mu f^{2}}
$$

where

$$
\mathrm{d}=\frac{\mathrm{L}+\ell}{2}
$$

For all the experiments reported, the criteria of Equation 29 were satisfied, and the diffusion layer thickness might be derived neglecting forced convection.

Standard heat transfer data $\mathrm{a}^{26}$ give the following Nusselt number correlations for free convection over a horizontal rectangular isothermal plate.

$$
\begin{array}{ll}
\overline{\mathrm{N}} \mathrm{u}_{\mathrm{f}}=0.54\left(\mathrm{Gr}_{\mathrm{f}} \mathrm{Pr}\right)^{1 / 4} & \text { laminar case } \\
& 2 \times 10^{4}<\mathrm{Gr}_{\mathrm{f}} \mathrm{Pr}<8 \times 10^{6} \\
\overline{\mathrm{N}} \mathrm{u}_{\mathrm{f}}=0.15\left(\mathrm{Gr}_{\mathrm{f}} \mathrm{Pr}\right)^{1 / 3} & \text { turbulent case } \\
& 8 \times 10^{6}<\mathrm{Gr}_{\mathrm{f}}^{\mathrm{Pr}<10^{11}}
\end{array}
$$

For the experiments reported, the laminar case holds. As a consequence of the unity of the Lewis number, the Prandt 1 number has also been assumed to be unity.

For the laminar case:

$$
\overline{N u}_{f}=0.54\left(\mathrm{Gr}_{f} \mathrm{Pr}\right)^{1 / 4}
$$

By definition of the Nusselt number

$$
\overline{\mathrm{N}} \mathrm{u}_{\mathrm{f}}=\frac{\mathrm{hd}}{\mathrm{k}}
$$

combining Equations 36 and 37 yields

$$
\frac{\mathrm{hd}}{\mathrm{k}}=0.54\left(\mathrm{Gr}_{\mathrm{f}}\right)^{1 / 4}
$$


Assuming an ideal gas in the gas phase above the burning polvmer

$$
\begin{aligned}
& \beta=\frac{1}{T_{f 1}} \\
& \Delta T=T_{f 1}-T_{S} \\
& \rho_{f}=\frac{P M}{\bar{R} T_{f i 1 m}}
\end{aligned}
$$

where $M$ is the molecular weight of the inlet gas and $P$ is the ahsolute pressure within the incinerator. Combining Equations 39,40 , and 41 into Equation 32 yields

$$
G r_{f}=\frac{g}{2}\left(\frac{P M}{\bar{R} \mu_{f}}\right)^{2}\left\{\frac{T_{f 1}-T_{s}}{T_{f 1}\left(T_{f 1}+T_{s}\right)^{2}}\right\}^{L L+\ell\}^{3}}
$$

By the definition of the heat transfer coefficient $h$

$$
\mathrm{h}=\frac{\mathrm{k}}{\delta}
$$

Combining Fquations 33,38 , and 43 yields

$$
\frac{\mathrm{K}}{\delta \mathrm{C}_{\mathrm{P}}}=\frac{\mathrm{h}}{\mathrm{C}_{\mathrm{p}}}=1.08\left(\frac{\mathrm{K}_{\mathrm{f}}}{\mathrm{C}_{\mathrm{p}}}\right)\left(\frac{1}{\mathrm{~L}+\ell}\right)\left\{\mathrm{Gr}_{\mathrm{f}}\right\}^{1 / 4}
$$

Then, comhining Fquations 42 and 44 vields

$$
\frac{K}{\delta C_{D}}=0.91\left(\frac{K}{C_{D}}\right)\left(\frac{P M}{R_{\mu}}\right)^{1 / 2}\left[\frac{g\left(T_{f l}-T_{S}\right)}{T_{f l}\left(T_{f l}+T_{S}\right)^{2}(L+\ell)}\right]^{1 / 4}
$$


Recalling Equations 27 and 28

$$
\dot{m}^{\prime \prime}=\frac{\mathrm{K}}{\delta \mathrm{C}_{\mathrm{p}}} \ln \left\{\frac{1+i\left(\mathrm{M}_{\mathrm{O}_{2}}\right)_{\infty} \Delta \mathrm{H}_{\mathrm{c}}+\mathrm{C}_{\mathrm{p}}\left(\mathrm{T}_{\mathrm{w}}-\mathrm{T}_{\mathrm{s}}\right)}{\mathrm{L}_{\mathrm{g}}-\frac{\sigma \mathrm{F}_{\mathrm{ws}}\left(\mathrm{A}_{\mathrm{w}} / \mathrm{A}_{\mathrm{s}}\right)\left(\mathrm{T}_{\mathrm{w}}{ }^{4}-\mathrm{T}_{\mathrm{s}}{ }^{4}\right)}{\dot{\mathrm{m}}^{\prime \prime}}}\right\}
$$

or

$$
\frac{\delta C_{p}}{K} \quad \dot{m}^{\prime \prime}-\ln \left\{\frac{1+i\left(M_{O_{2}}\right)_{\infty} \Delta H_{c} \dot{m}^{\prime \prime}+C_{p}\left(T_{w}-T_{s}\right) \dot{m}^{\prime \prime}}{\dot{m}^{\prime \prime} L_{g}-\sigma F_{w s}\left(A_{w} / A_{s}\right)\left(T_{w}{ }^{4}-T_{s}^{4}\right)}\right\}=0
$$

Equation 45 may be substituted into Equation 47 and $\dot{m}^{\prime \prime}$ solved by the Newton-Rhaphson method. At low-to-moderate furnace wall temperatures, combustion can play an important role in the burning rate. At high furnace temperatures, thermal radiation dominates; consequently, burning rates at very high temperatures are predicted by Equation 9 alone.

\section{Off-Gas Composition}

The calculation of the composition of the off-gas from the laboratory-scale incinerator is complicated. The problem may be attempted on three model levels of increasing difficulty and accuracy. In order of increasing difficulty these models would be listed as follows:

1. Stoichiometric

2. Chemical Equilibrium

3. Chemical Kinetic

\section{Stoichiometric Model}

The stoichiometric model follows directly from the assumptions used in the combustion rate model discussed previously where the mass flux of polymer being consumed, $\dot{m}$ ", is calculated. From the value of $\dot{\mathrm{m}}^{\prime \prime}$, the mass flow rate of fuel, $\dot{\mathrm{m}}_{\mathrm{F}}$, may be calculated.

$$
\dot{m}_{F}=\dot{m}^{\prime \prime} A_{S}
$$


If the primary air Reynolds number is known, then the mass flow rate of air into the incinerator may be calculated as

$$
\dot{\mathrm{m}}_{\mathrm{A}}=\operatorname{Re}_{\mathrm{H}} \mu_{\mathrm{g}} \mathrm{H}\left(\frac{\pi}{4}\right)^{1 / 2}
$$

where $\mu_{g}$, the viscosity of the primary air is taken at a temperature $\mathrm{Tg} \cong 100^{\circ} \mathrm{C}$. Assuming all of the fuel is either converted to $\mathrm{CO}_{2}$ and $\mathrm{H}_{2} \mathrm{O}$ or remains as unburned fuel, the following of $\mathrm{f}-\mathrm{gas}$ mass fractions may be calculated.

$$
\begin{aligned}
& \left(\mathrm{M}_{\mathrm{N}_{2}}\right)_{\text {O.G. }}=\frac{\left[1-\left(\mathrm{M}_{\mathrm{O}_{2}}\right)_{\delta}\right] \dot{\mathrm{m}}_{\mathrm{A}}}{\dot{\mathrm{m}}_{\mathrm{A}}+\dot{\mathrm{m}}_{\mathrm{F}}} \\
& \left({\underset{\text { UUEL }}{\text { UNBUED }}}_{\text {O.G. }}=\frac{\dot{\mathrm{m}}_{\mathrm{F}}-i\left(\mathrm{M}_{\mathrm{O}_{2}}\right)_{\delta} \dot{\mathrm{m}}_{\mathrm{A}}}{\dot{\mathrm{m}}_{\mathrm{A}}+\dot{\mathrm{m}}_{\mathrm{F}}}\right. \\
& \left(\begin{array}{l}
M_{\text {COMBUSTION }} \\
\text { PRODUCTS }
\end{array}\right)_{\text {O.G. }}=1-\left(M_{N_{2}}\right)_{0 . G .}-\left(\frac{M_{\text {UNBURNED }}}{\text { FUEL }}\right)_{0 . G .}
\end{aligned}
$$

In the case where there is more than the stoichiometric oxygen requirement, then $\mathrm{O}_{2}$ will exist in the off-gas in place of unburned fuel. The following off-gas mass fractions may be calculated.

$$
\begin{aligned}
& \left(\mathrm{M}_{\mathrm{N}_{2}}\right)_{0 . \mathrm{G} .}=\frac{\left[1-\left(\mathrm{M}_{\mathrm{O}_{2}}\right)_{\delta}\right] \dot{\mathrm{m}}_{\mathrm{A}}}{\dot{\mathrm{m}}_{\mathrm{A}}+\dot{\mathrm{m}}_{\mathrm{F}}} \\
& \left(\mathrm{M}_{\mathrm{O}_{2}}\right)_{0 . \mathrm{G} .}=\frac{\left(\mathrm{M}_{\mathrm{O}_{2}}\right)_{\delta} \dot{\mathrm{m}}_{\mathrm{A}}-\frac{\dot{\mathrm{m}}_{\mathrm{F}}}{\dot{\mathrm{i}}}}{\dot{\mathrm{m}}_{\mathrm{A}}+\dot{\mathrm{m}}_{\mathrm{F}}} \\
& \left(\begin{array}{c}
\mathrm{M}_{\text {COMBUSTION }} \\
\text { PRODUCTS }
\end{array}\right)_{\text {O.G. }}=1-\left(\mathrm{M}_{\mathrm{N}_{2}}\right)_{0 . G .}-\left(\mathrm{M}_{\mathrm{O}_{2}}\right)_{0 . G} .
\end{aligned}
$$




\section{DISCUSSION OF RESULTS AND CONCLUSIONS}

\section{Pyrolysis in the Laboratory-Scale Incinerator}

The pyrolysis rate data as tabulated in Tables 1,3 , and 5 for polyethylene, cellulose, and latex were fitted to the pyrolysis model, Equation 9, to obtain values of $\mathrm{L}_{\mathrm{g}}$ and $\mathrm{T}_{\mathrm{s}}$ for each material. Figures 16,17 , and 18 show the experimental pyrolysis rate vs. incinerator wall temperature and the fitted curves. It was observed that inlet gas Reynolds number, $R_{H}$, has no effect on the observed pyrolysis rate. This result is consistent with the assumption in the pyrolysis model that convective heat transfer is negligible compared to energy transfer by thermal radiation. This is true because the convective heat transfer $h$ is a function of $\operatorname{Re}_{\mathrm{L}}$, which is proportional to $\operatorname{Re}_{\mathrm{H}}$ by Equation 30 . Table 10 ists the fitted values for $\mathrm{L}_{s}$ and $\mathrm{T}_{s}$ of this study, and values obtained for similar polymers by Tewarson. ${ }^{12}$ The results of this study agree with Tewarson's data.

TABLE 10

Effective Heats of Gasification and Characteristic Polymer Surface Temperature

\begin{tabular}{|c|c|c|c|c|}
\hline \multirow[b]{2}{*}{ Material } & \multicolumn{2}{|c|}{$\begin{array}{l}\text { Effective Heat } \\
\text { of Gasification, } \\
\mathrm{kJ} / \mathrm{g}\end{array}$} & \multicolumn{2}{|c|}{$\begin{array}{l}\text { Characteristic } \\
\text { Surface Temperature, } \\
{ }^{\circ} \mathrm{K}\end{array}$} \\
\hline & Tewarson 12 & This Work & Tewarson & This Work \\
\hline Cellulose & 3.55 & 2.54 & - & 521 \\
\hline Polyethylene & 2.32 & 1.13 & 761 & 748 \\
\hline Latex & - & 0.292 & - & 683 \\
\hline
\end{tabular}




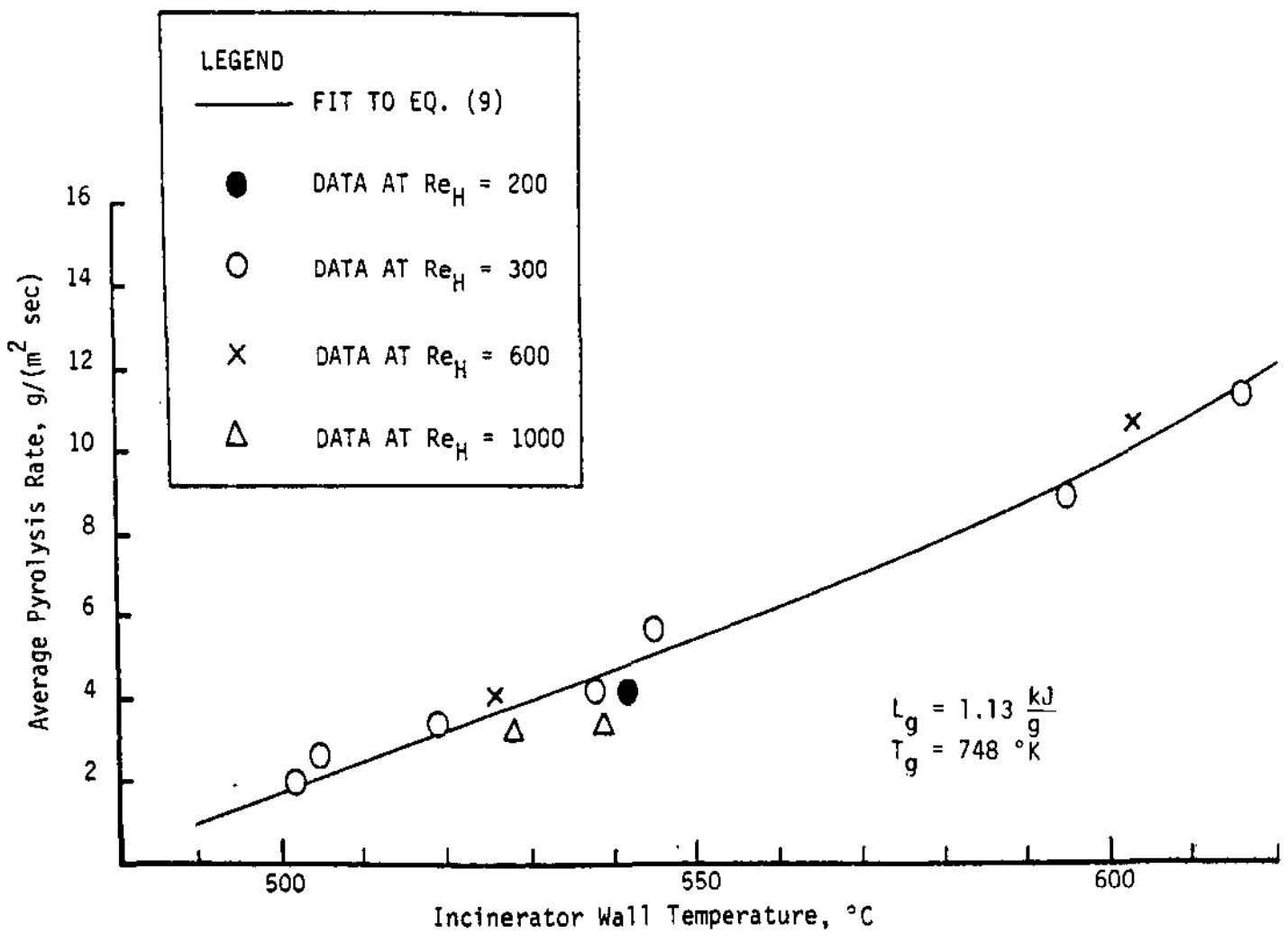

RIGURE 16. Average Pyrolysis Rate of Polyethylene 


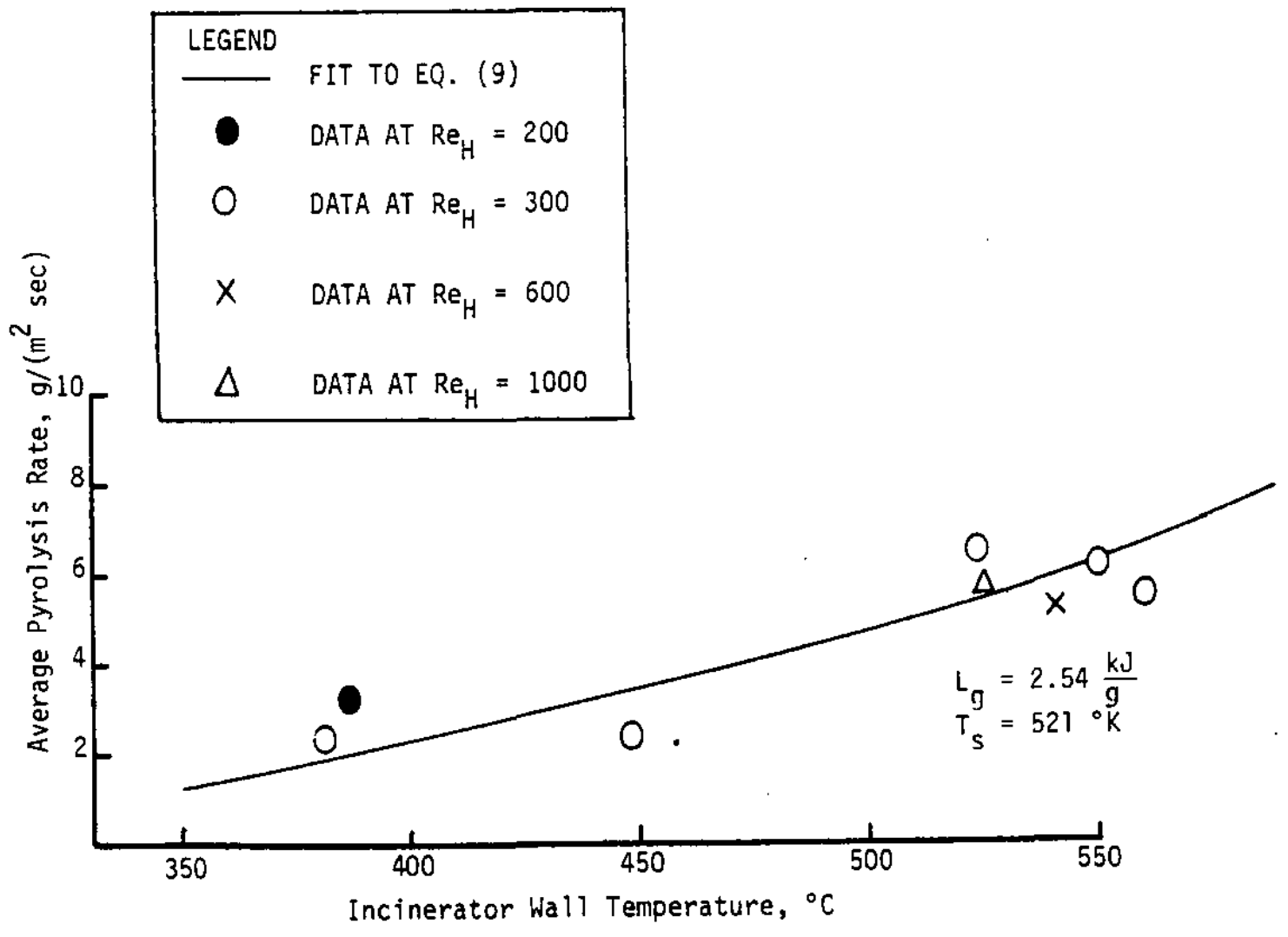

FIGURE 17. Average Pyrolysis Rate of Cellulose 


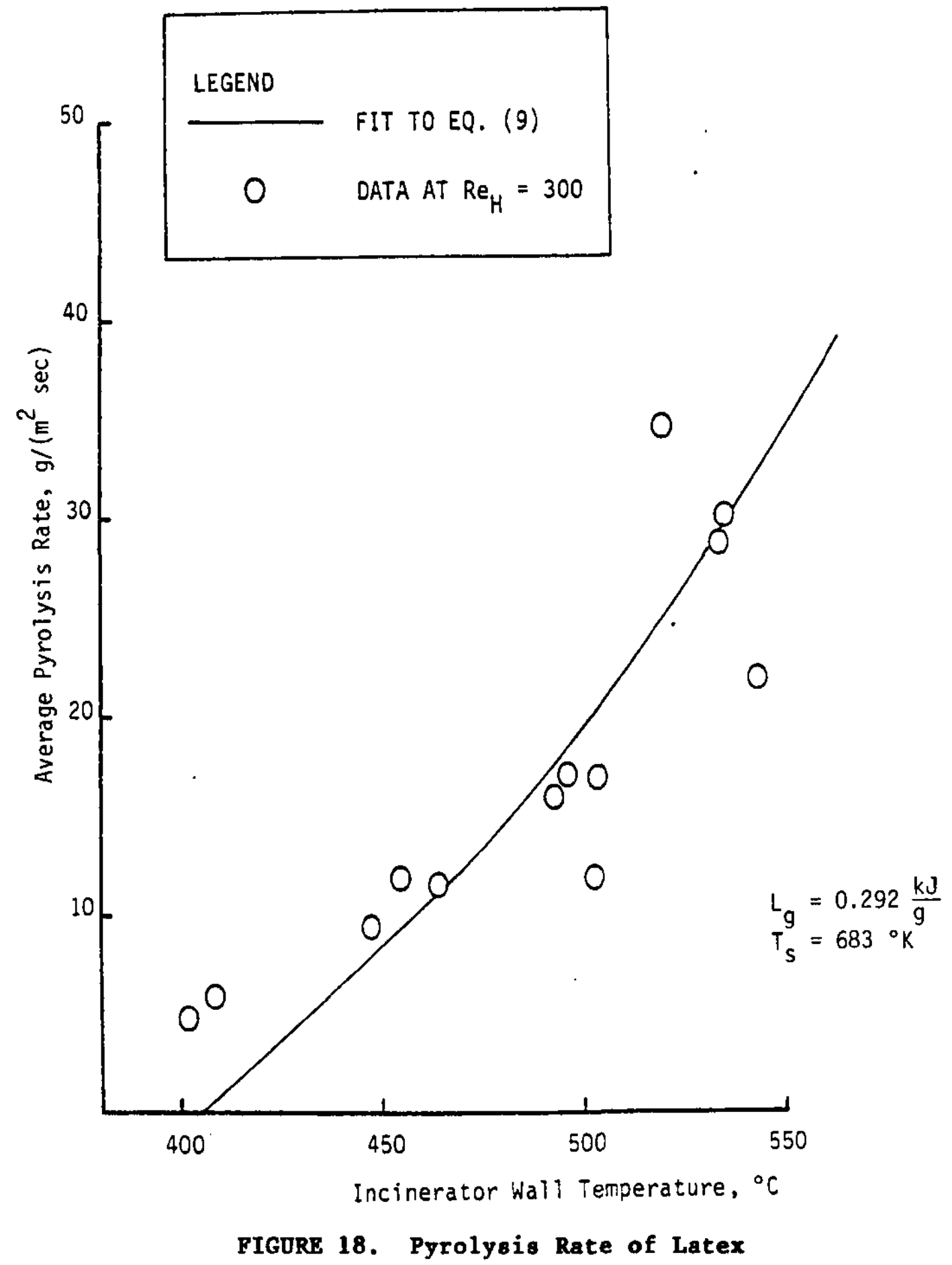




\section{Combustion in the Laboratory-Scale Incinerator}

Table 11 shows the physical data used with the mass burning rate formulation of Equations 45 and 47 . The burning rate solution was found to be weakly sensitive to the assumed flame temperature and heat of combustion. The fact that they were taken from the literature for similar materials does not appear to be critical. Computer solutions for the case of polyethylene, cellulose, and latex combustion with primary air oxygen concentration of $21 \mathrm{~mol} \%$ are shown in Figures 1, 2, and 3 . Also shown in the same figures are the experimental combustion rates at different primary air Reynolds numbers, $\operatorname{Re}_{\mathrm{H}}$. Burning rates are observed to be independent of the primary air Reynolds number; therefore, the burning rate of any waste material will be independent of the mass flow rate of primary air as long as free convection dominates forced convection (Equation 29). Experimental burning rates and the theory agree for polyethylene. For latex and cellulose, the theory exceeds the experimental burning rate.

It should be noted that although burning rate is independent of inlet gas Reynolds number, the composition of the off-gas from the primary stage of the incinerator will be affected by the mass flow rate of primary air and, consequently, by the primary air Reynolds number. This effect is illustrated by the calculated off-gas mass fractions from the combustion of polyethylene at a Reynolds number of 100 and 600 (Figures 19 and 20).

\section{Combustion in the Primary of the ICTF}

The ultimate value of the burning rate model, and computer code based on that model, can only be judged by comparing the results of the model with experimental data from the full-scale ICTF. Experimental burning rate data for the three polymers of interest as obtained on the ICTF by SRL staff are tabulated in

"Experimental Data." These experiments were performed under conditions of constant primary air of $12 \mathrm{scfm}$ at several primary wall temperatures. Figure 21 shows the geometry of the ICTF primary. Also shown is the assumed initial configuration of the 
TABLE 11

Physical Data Used in Theory

\begin{tabular}{|c|c|c|c|c|c|c|c|c|}
\hline & Data & & Polyethylene & & Cellulose & & Latex & \\
\hline & $\begin{array}{l}\text { Text } \\
\text { Symbol }\end{array}$ & Units & Value & $\begin{array}{l}\text { Reference } \\
\text { Source }\end{array}$ & Value & $\begin{array}{l}\text { Reference } \\
\text { Source }\end{array}$ & Value & $\begin{array}{l}\text { Reference } \\
\text { Source }\end{array}$ \\
\hline & $\mathbf{A}_{\boldsymbol{s}}$ & $\mathrm{m}^{2}$ & 0.0102 & Measured & 0.0102 & Measured & 0.0102 & Measured \\
\hline & $A_{w}$ & $\mathrm{~m}^{2}$ & 0.0552 & Measured & 0.0552 & Measured & 0.0552 & Me asured \\
\hline & g & $\mathrm{m} / \mathrm{sec}^{2}$ & 9.800 & - & 9.800 & - & 9.800 & - \\
\hline & $\mathbf{H}$ & $\mathbf{m}$ & 0.1016 & Measured & 0.1016 & Measured & 0.1016 & Measured \\
\hline & $\Delta \mathrm{H}_{\mathrm{c}}$ & $\mathrm{J} / \mathrm{g}$ & 47,088 & - & 18,681 & - & 43,575 & - \\
\hline & i & & 0.292 & Equation 12 & 0.844 & Equation 12 & 0.3041 & Equation 12 \\
\hline , & $\ell$ & m & 0.0762 & Measured & 0.0762 & Measured & 0.0762 & Measured \\
\hline & L & $m$ & 0.1397 & Measured & 0.1397 & Measured & 0.1397 & Measured \\
\hline & $\mathrm{L}_{\mathrm{g}}$ & $\mathrm{kJ} / \mathrm{g}$ & 1.130 & Experimental & 2.54 & Experimental & 0.292 & Experimental \\
\hline & $\mathbf{P}$ & $N / m^{2}$ & 101,353 & Measured & 101,353 & Measured & 101,353 & Measured \\
\hline & $\overline{\mathbf{R}}$ & $\mathrm{N}-\mathrm{m} /\left(\right.$ mole $\left.{ }^{\circ} \mathrm{K}\right)$ & 8.314 & - & 8.314 & - & 8.314 & - \\
\hline & $\mathrm{Tg}$ & ${ }^{\circ} \mathrm{K}$ & 373 & Typical & 373 & Typical & 373 & Typical \\
\hline & $T_{f 1}$ & ${ }^{\circ} \mathrm{K}$ & 1,800 & Assumed & 1,800 & Assumed & 1,800 & Assumed \\
\hline & $\mathrm{T}_{\mathbf{s}}$ & ${ }^{\circ} \mathrm{K}$ & 748 & Experimental & 521 & Experimental & 683 & Experimental \\
\hline & $\varepsilon_{w}$ & $\sim$ & 0.55 & - & 0.55 & - & 0.55 & - \\
\hline & $\sigma$ & $\mathrm{kJ} /\left(\mathrm{m}^{2} \mathrm{sec}{ }^{\circ} \mathrm{K}^{4}\right)$ & $5.669 \times 10^{-11}$ & - & $5.669 \times 10^{-11}$ & - & $5.669 \times 10^{-11}$ & - \\
\hline
\end{tabular}




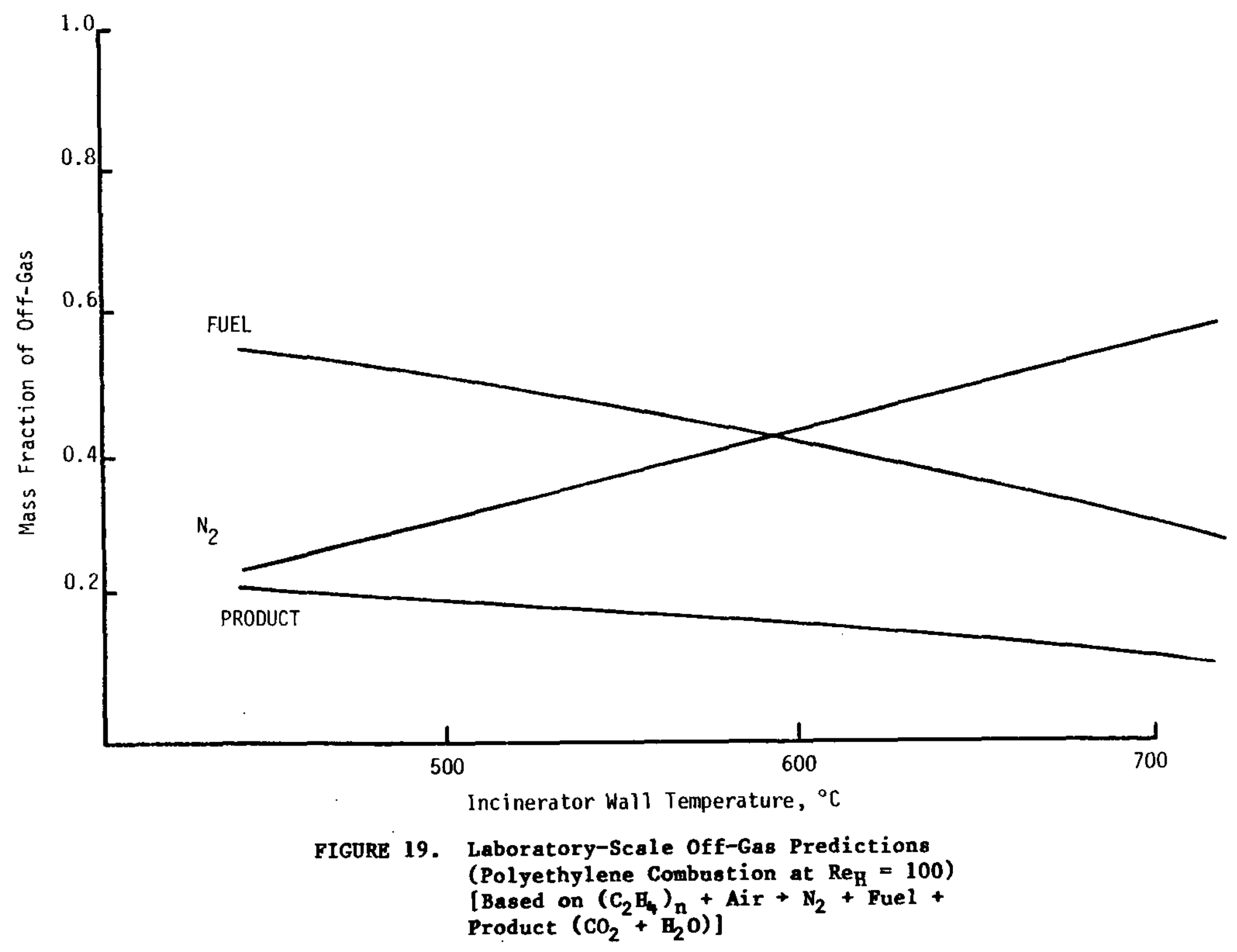




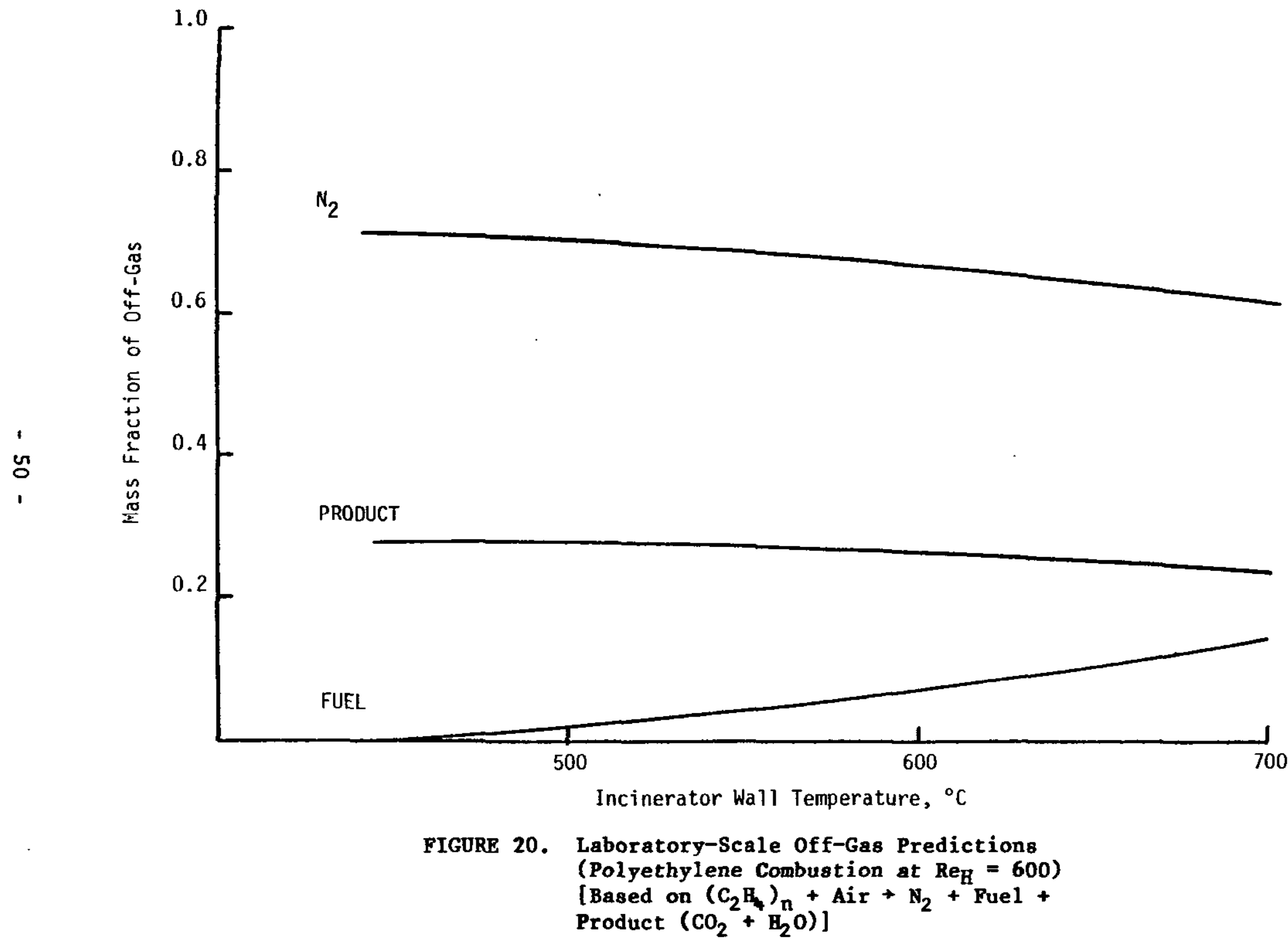




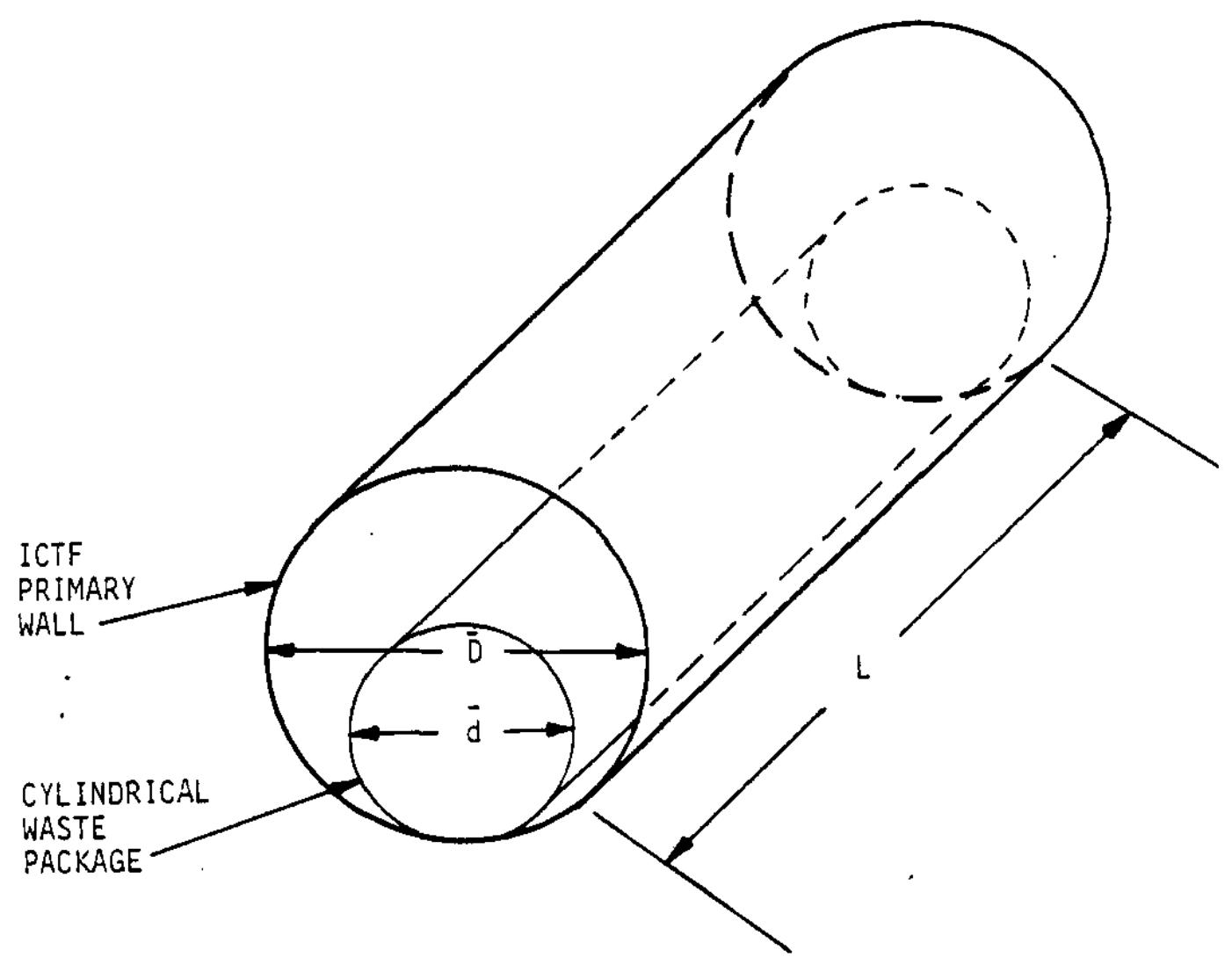

FIGURE 21. Geometry of the ICTF Primary and Waste 
waste prior to combustion. In order to use the analytical model, which is based on constant waste surface area during combustion, the following definitions have been used to develop a computer code:

$$
\begin{aligned}
& \ell=\pi \bar{d} / 2 \\
& A_{w}=\pi \vec{D} L \\
& A_{s}=\pi \bar{d} L / 2
\end{aligned}
$$

where for the ICTF

$$
\begin{aligned}
\varepsilon w & =0.86 \\
\bar{D} & =0.216 \mathrm{~m}
\end{aligned}
$$

Table 12 gives the average value of the waste packet diameter and length for each of the polymer samples whose rates are tabulated in Tables 7,8, and 9. Figures 4, 5, and 6 show the experimental burning rates plotted versus primary wall temperature for polyethylene, latex, and cellulose samples. Also shown in the figures are the burning rates as predicted by the computer code with the dimensional modifications as indicated in Equations 56,57 , and 58 . The code and experiments agree for polyethylene and latex, and the code provides an upper limit for the case of cellulose.

Based on the stoichiometric model ("Off-gas Composition" of this section), the mass fraction of the off-gas products from the ICTF primary may be calculated. Figures 7 and 8 show the primary off-gas compositions calculated for the case of $11 \mathrm{scfm}$ primary air. Results for 200-g samples of polyethylene and 100-g samples of latex are shown. It is clear that fuel-rich combustion occurs in both cases thereby requiring secondary air. The secondary air required may be easily calculated, assuming that the unburned fuel in the primary chamber off-gas has an average composition identical to the original solid waste. This method should provide an adequate estimation of the air requirement; however, it must be realized that the unburned fuel from the primary chamber off-gas will actually consist of several species. Gas-phase pyrolysis, recombinations, and incomplete combustion will result in soot formation, carbon monoxide, and a multitude of hydrocarbon species, which with the 


\section{TABLE 12}

ICTF Calculational Parameters

\begin{tabular}{|c|c|c|c|c|}
\hline Material & $\mathrm{L}_{\mathrm{g}}$ & $\mathrm{T}_{\mathbf{s}}$ & $\Delta \mathrm{H}_{\mathrm{c}}$ & i \\
\hline Polyethylene & 1.13 & 748 & 47,088 & 0.292 \\
\hline Cellulose & 2.54 & 531 & 18,681 & 0.844 \\
\hline Latex & 0.292 & 683 & 43,575 & 0.3041 \\
\hline
\end{tabular}

Material

$\overline{\mathrm{d}}, \mathrm{m} \quad \mathrm{L}, \mathrm{m}$

Latex

Average

Average

$(100 \mathrm{~g})$

$0.0425 \mathrm{~m} \quad 0.2524 \mathrm{~m}$

Cellulose

(200 g)

$0.1073 \mathrm{~m}$

$0.1988 \mathrm{~m}$

Polyethylene

(200 g) long

$0.0622 \mathrm{~m} \quad 0.2642 \mathrm{~m}$

Polyethylene

(100 g) long

$0.0425 \mathrm{~m} \quad 0.2540 \mathrm{~m}$

Polyethylene

$(100 \mathrm{~g})$ short $0.0593 \mathrm{~m} 0.1661 \mathrm{~m}$ 
details of the secondary will determine secondary air required for complete combustion. The next section reports the results of gas sampling experiments in which the off-gas products from the laboratory- scale incinerator have been measured under fuel-rich combustion conditions.

\section{Off-Gas Analysis from the Laboratory-Scale Incinerator}

\section{Preliminary Pyrolysis Experiments}

Early experiments on the pyrolysis of polyethylene in an argon environment were performed in the experimental facility described in earlier reports. ${ }^{6,7}$ The sampling and analysis methods used were the same as discussed in "Experimental Procedures," except that the sample line was heated to $110^{\circ} \mathrm{C}$, and no filter was provided between the sample line and the gas chromatograph. Therefore, condensation of high molecular weight hydrocarbons was prevented in the sampling system before the hydrocarbons were injected into the gas chromatograph.

The experiments were performed in an initial environment of argon with no flow into the furnace from the outside. A gas vent in the furnace allowed the pyrolysis products to be vented to the outside. Figure 22 shows the composition of the off-gas from the furnace as a function of time. Summing the mole fractions to one indicated that unidentified species had been formed during the initial part of the pyrolysis process. Figure 23 shows this result. In the absence of oxygen, pyrolysis is kinetically controlled. In particular, high molecular weight species are formed in the initial part of the pyrolysis process, and as time goes on, these species react in the gas phase above the polymer to form methane and hydrogen.

\section{Combustion of Polyethylene}

The off-gas from the combustion of 50-g samples of polyethylene, in the laboratory-scale incinerator, was sampled as a function of time as described in "Off-gas Sampling and Analysis." Typical composition profiles are shown in Figures 24 through 26 . With a larger initial sample weight and subsequent longer burning time, the furnace wall temperatures could not be maintained constant. This is, of course, due to heating of the walls by the combustion process. Figure 9 shows a qualitative composite of the off-gas from polyethylene combustion. The cooled sample was filtered, and only trace amounts of condensibles would be expected. As the burning rate increases to a peak and then decreases, oxygen also varies, with time, reaching a minimum at a time when one would observe a maximum instantaneous burning rate. As oxygen becomes 
MAJOR COPAPONENTS
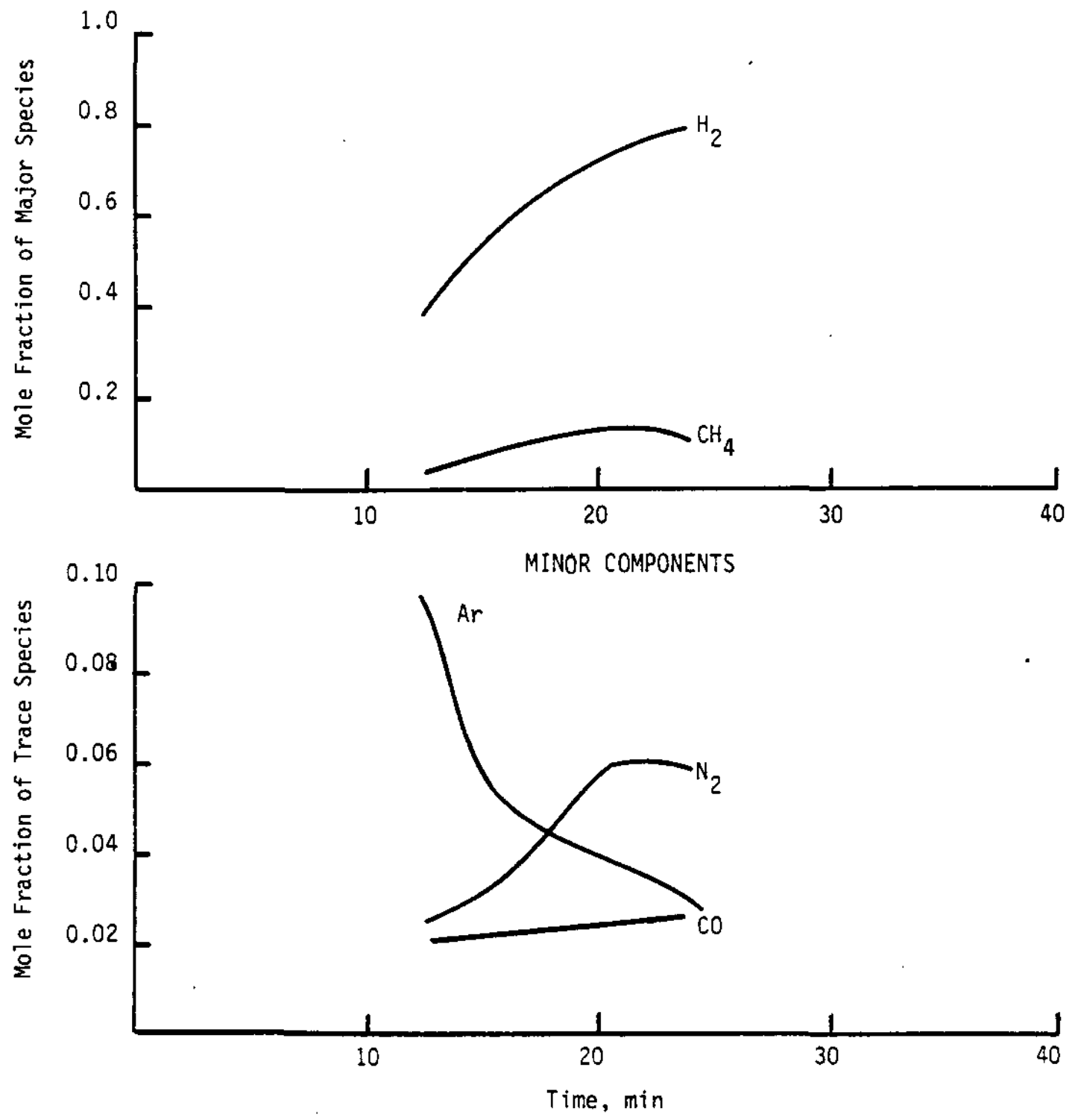

FIGURE 22. Pyrolysis of Polyethylene in Argon $\left(T_{w}=630^{\circ} \mathrm{C}\right)$ 


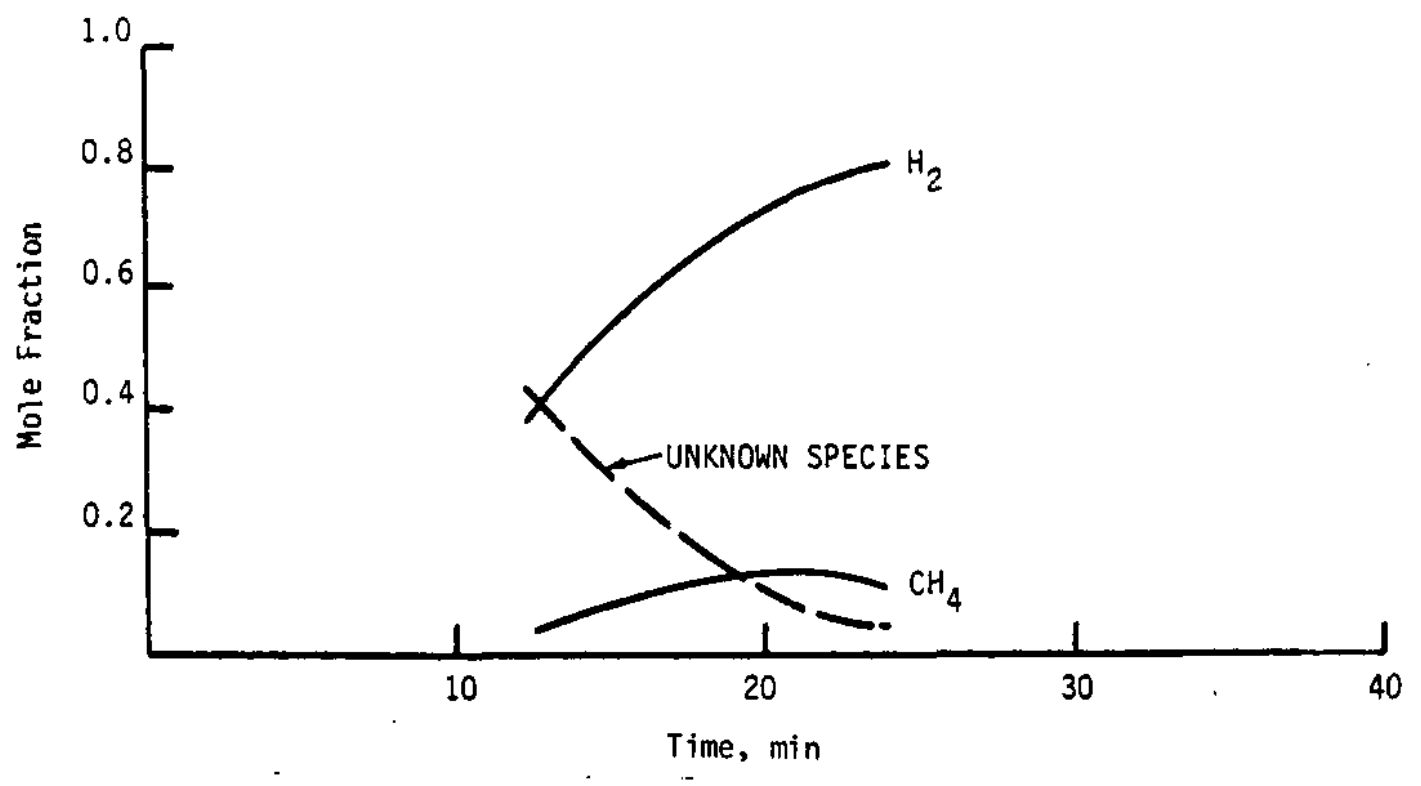

PIGORE 23. Pyrolysis of Polyethylene in Argon $\left(T_{w}-630^{\circ} \mathrm{C}\right)$ 


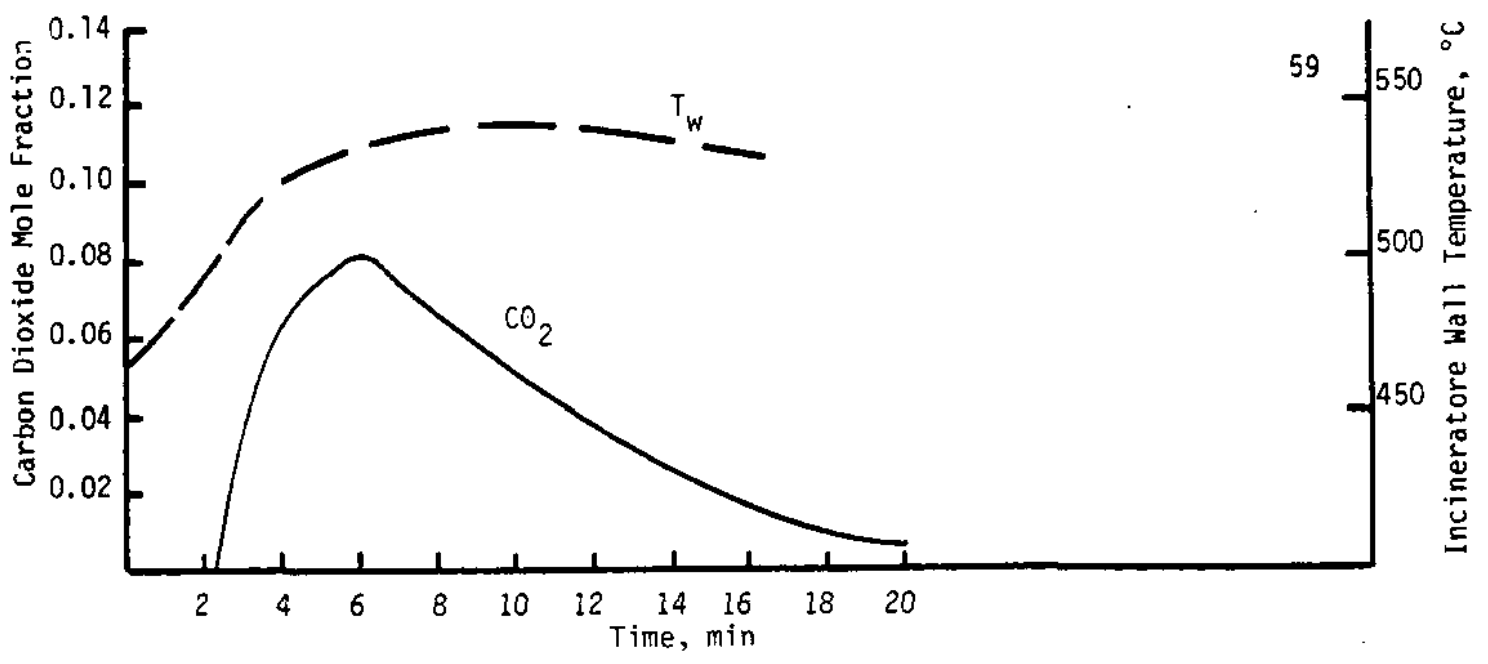

FIGURE 24, Off-Gas Analysis of the Laboratory-Scale Combustion of Polyethylene, First Test $\left(\operatorname{Re}_{\mathrm{H}}=100\right)($ Sample Weight $=50 \mathrm{~g})$ 


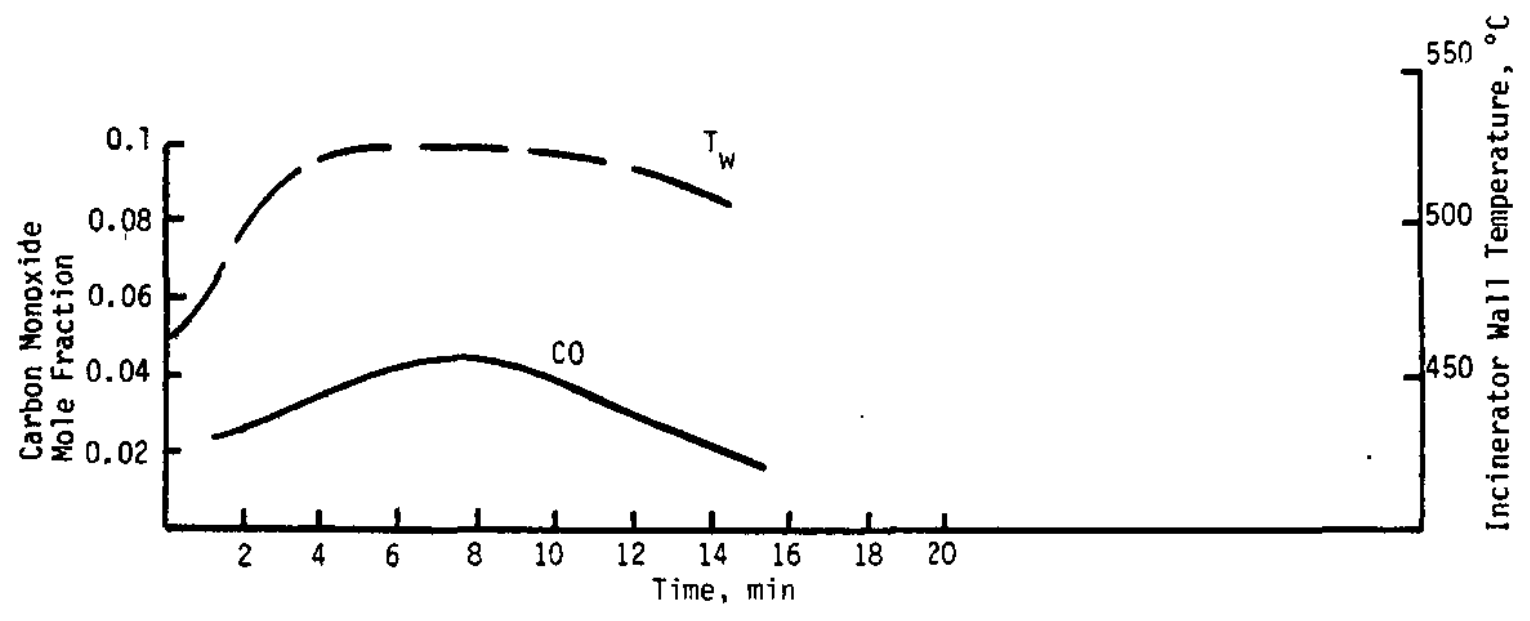

FIGURE 25. Off-Gas Analysis of the Laboratory-Scale Combustion of Polyethylene, Second Test

$\left(\operatorname{Re}_{\mathrm{H}}=100\right)($ Sample Weight $=50 \mathrm{~g})$ 


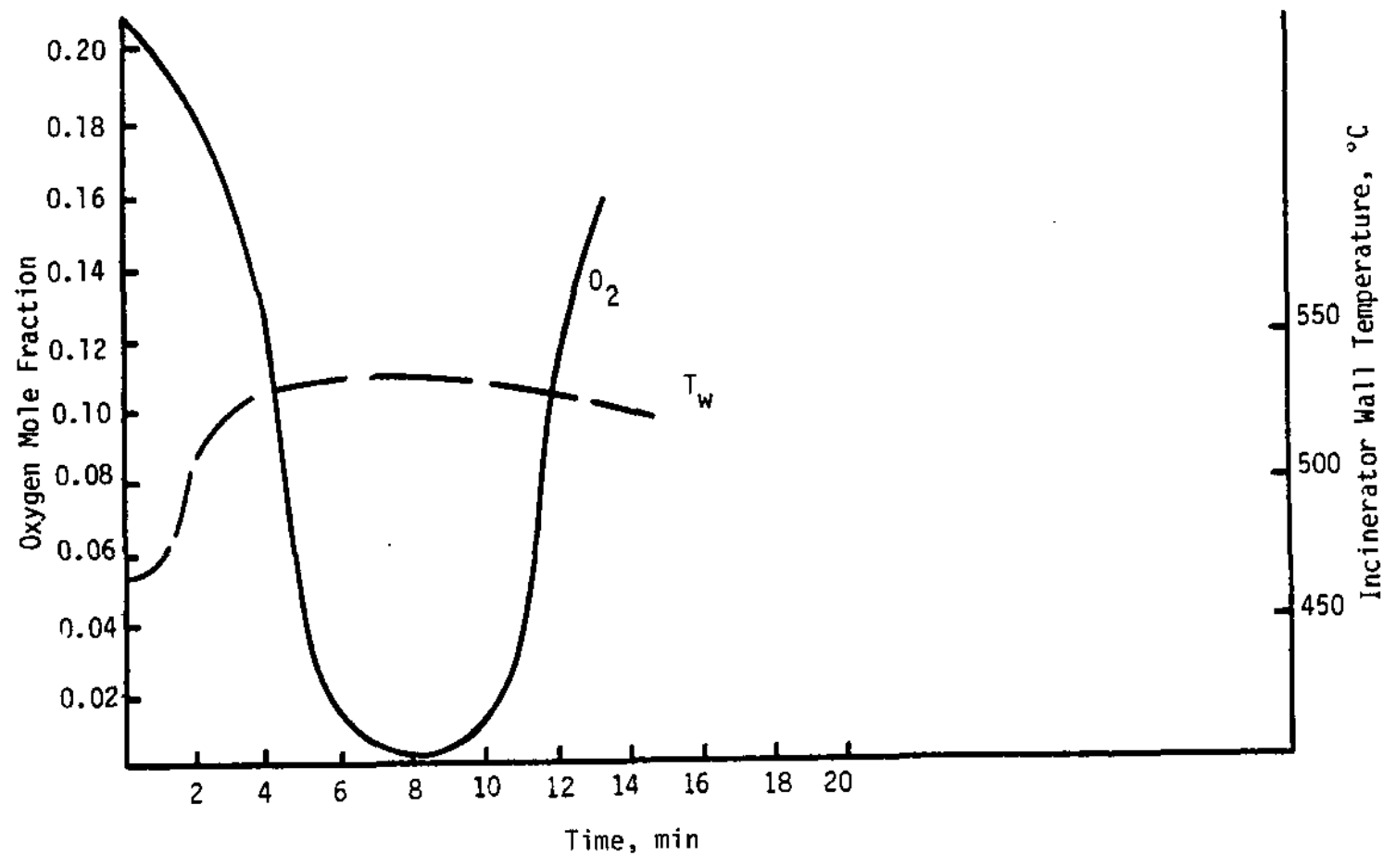

FIGURE 26. Off-Gas Analysis of the Laboratory-Scale Combustion of Polyethylene, Third Test

$\left(\operatorname{Re}_{\mathrm{H}}=100\right)($ Sample Weight $=50 \mathrm{~g})$ 
depleted, less oxygen is available for the complete combustion of $\mathrm{CO}$ to $\mathrm{CO}_{2}$ so that the $\mathrm{CO}_{2}$ profile drops off while the $\mathrm{CO}$ profile continues to peak when $\mathrm{O}_{2}$ reaches its minimum.

Two unidentified peaks were observed on the chromosorb ${ }^{m}-102$ (Johns-Manville Corporation, Denver, CO.) column, when the $\mathrm{O}_{2}$ peak was at its minimum. These peaks were determined to be species other than $\mathrm{CH}_{4}, \mathrm{~N}_{2}, \mathrm{O}_{2}, \mathrm{CO}, \mathrm{CO}_{2}$, and $\mathrm{H}_{2} \mathrm{O}$ by injection of pure samples of these species into the column. A batch sample was taken, however, which was later analyzed by a scanning infrared analyzer (the IR spectra are shown in Figure 10). Using tabulated spectra for various species, the sample was found to contain toluene, hexane, benzene, ethylene, and acetylene. These species are believed to make up the unburned fuel that is predicted as an off-gas product in the stoichiometric model of "Off-Gas Composition" of this section. 


\section{NOMENCLATURE}

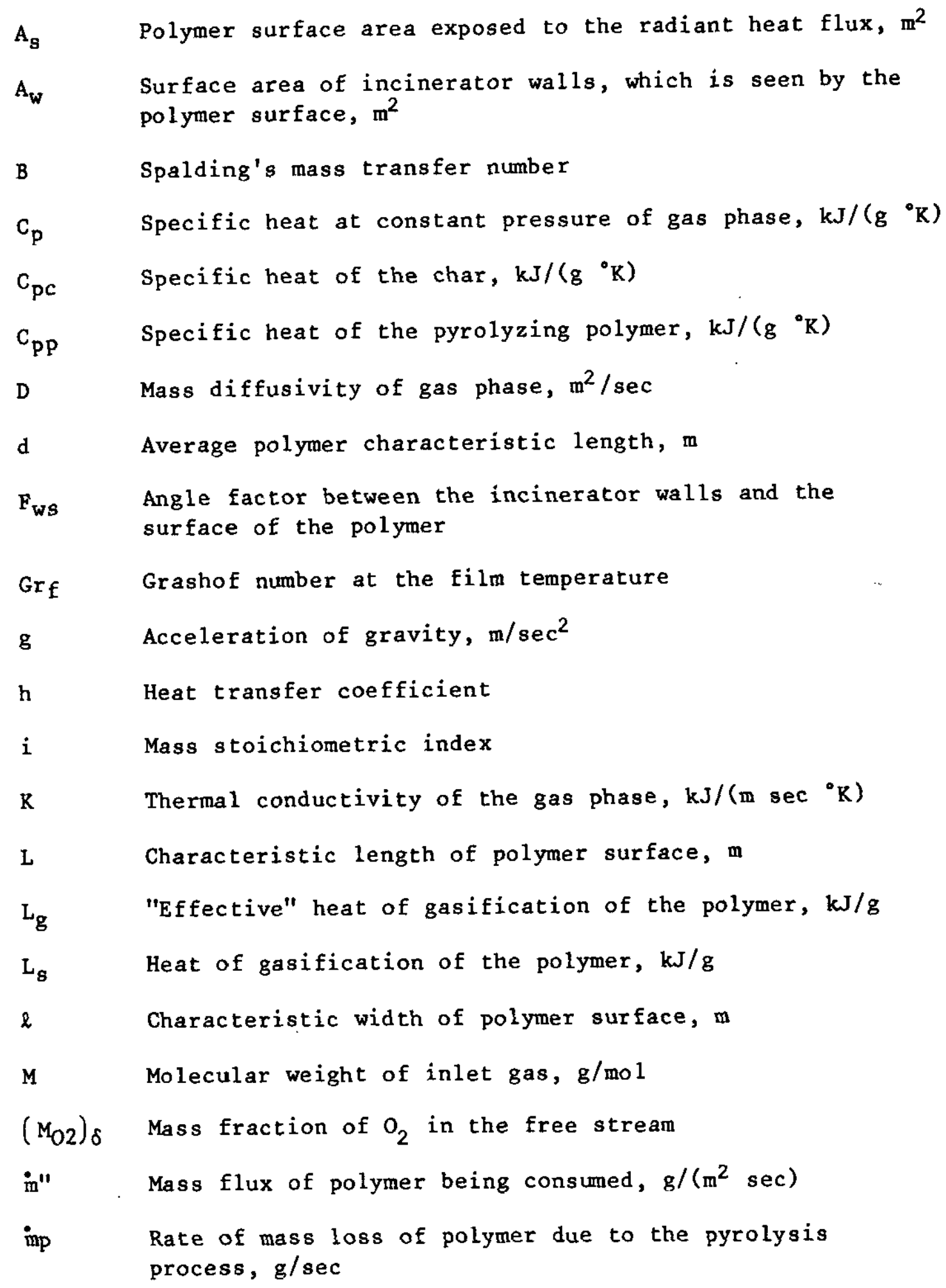


MOMENCLATURE (Continued)

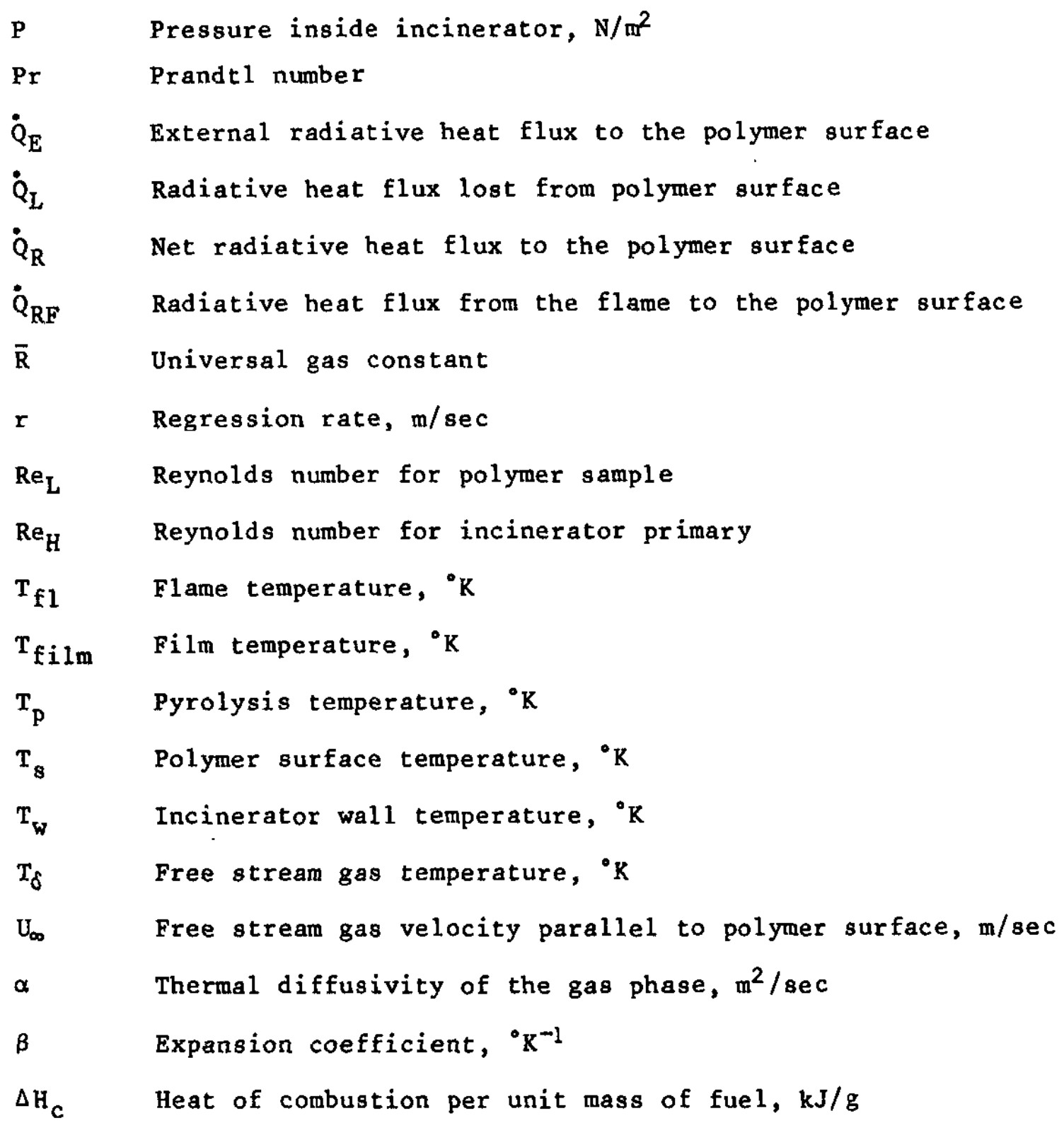




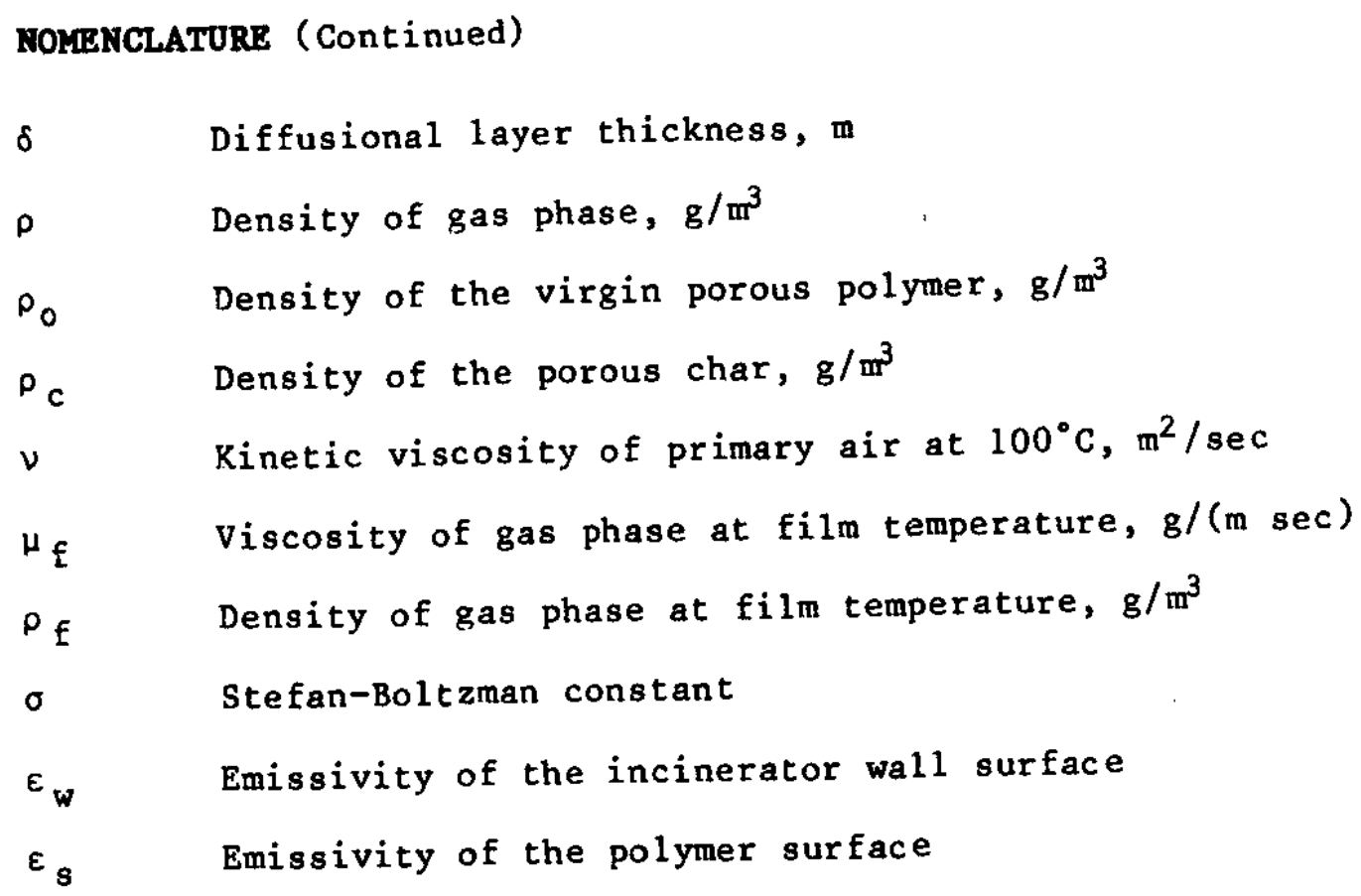




\section{ACKMOWLEDGMENTS}

The author would like to express his gratitude to E. L. Albenesius for his trust and support during the course of this and previous research. In addition, the ultimate relevancy of the work to practical waste incinerator design is, to a large part, a result of the many suggestions and contributions of H. E. Hootman. 
REFERENCES

1. H. E. Hootman, D. J. Trapp, J. H. Warren, and L. O. Dwor janyn. "Operation of a Prototype Alpha Solid Waste Incinerator." Proceedings of the $27 \mathrm{th}$ Conference on Remote Systems Technology, 1979 Winter Meeting, San Francisco, California, p. 405 American Nuclear Society, La Grange, Park, IL (1979).

2. D. I. Orloff. "Pyrolysis Model for an Alpha Waste Incinerat or Prototype." J. of Energy 3 (2), 90-94 (1979).

3. D. I. Orloff. Burning Rates of Porous Polymer Mixtures for Alpha Waste Incineration. CIR Report CIR-79-2, Center for Industrial Research, College of Engineering, University of South Carolina, Columbia, SC (1979).

4. A. F. Roberts. "Problems Associated with the Theoretical Analysis of the Burning of Wood." 13th Symposium (Internationa1) on Combustion, pp. 893-903, The Combustion Institute, Pittsburgh, PA (1971).

5. S. K. Brauman. "Polymer Degradation and Combustion." J. Polm. Sci. 15, 1507-9 (1977).

6. D. I. Orloff. Pyrolysis and Partial Combustion of Single Component Porous Wastes for Alpha Waste Incinerator Scale Up. CIR Report CIR-78-4, Center for Industrial Research, College of Engineering, University of South Carolina, Columbia, SC (1978).

7. D. I. Orloff. Pyrolysis of Porous Polymer Mixtures. CIR Report CIR-79-1, Center for Industrial Research, College of Engineering, University of South Carolina, Columbia, SC (1979).

8. A. Tewarson and R. F. Pion. "Flammability of Plastics I. Burning Intensity." Combust, and Flame 26, 85-103 (1976).

9. A. Tewarson. "Heat Release Rates from Samples of Polymethylmethacrylate and Polystyrene Burning in Normal Air." Fire and Mater. 1, 90-96 (1976).

10. A. Tewarson and F. Taminini. Research and Development for a Laboratory-Scale Flammability Test Method for Cellular Plastics. FMR Report FMRC-22524, Factory Mutual Research, Norwood, MA (1976). 
11. A. Tewarson and R. F. Pion. A Laboratory-Scale Test Method for the Measurement of Flamability Parameters. FMR Report FMRC-22524, Factory Mutual Research, Norwood, MA (1977).

12. A. Tewarson. Experimental Evaluation of Flammability Parameters of Polymeric Materials. FMR Report FMRC J.I.1A6R1.RCRC 79-T-9, Factory Mutual Research, Norwood, MA (1979).

13. R. C. Corlett. "Interactions Between Flames and Condensed Phase Matter." Heat Transfer in Fires, Chapter 1. Ed. P. L. Blackshear, John Wiley \& Sons, New York, NY (1974).

14. I. Glassman. The Mass Burning Rate of Polymeric Materials. CES Report 23, Center for Environmental Studies, Princeton University, Princeton, NJ (1975).

15. A. M. Kanury. "Modeling of Pool Fires with a Variety of Polymers." 15th Symposium (International) on Combustion, p. 193, The Combustion Institute, Pittsburgh, PA (1974).

16. I. Glass. "Some Perceptions on Condensed Phase Flame Spread and Mass Burning." J. of Fire and Flammability 9 , 88-89 (1978).

17. A. Tewarson. "Reply to Comments of Glassman on our Paper." Combustion and Flame 29, 107-109 (1977).

18. A. Tewarson and R. F. Pion. "Comments on: Flammability of Plastics - I. Burning Intensity." Combust. and Flame 29, 103-105 (1977).

19. A. T. Modak and P. A. Croce. "Plastic Pool Fires." Combust. and Flame 30, 251-265 (1977).

20. P. Joulain, J. M. Most, Y. Fuseau, and B. Sztal. "Influence of Coupled Convection, Conduction and Radiation Heat Transfer on the Burning of Plastic." 17th Symposium (International) on Combustion, p. 1041, The Combustion Institute, Pittsburgh, PA (1979).

21. G. H. Markstein. "Relative Properties of Plastic Fires." 17 th Symposium (International) on Combustion, p. 1053, The Combustion Institute, Pittsburgh, PA (1979).

22. D. J. Holve and R. F. Sawyer. "Diffusion Controlled Combustion of Polymers." 15th Symposium (International) on Combustion, p. 351, The Combustion Institute, Pittsburgh, PA (1974). 
23. W. W. Yuen and C. L. Tien. "A Simple Calculation Scheme for the Luminous Flame Emissivity." 16th Symposium (International) on Combustion, p. 1481, The Combustion Institute, Pittsburgh, PA (1977).

24. J. DeRis. "Fire Radiation - A Review." 17th Symposium (International) on Combustion, p. 1003, The Combustion Institute Pittsburgh, PA (1979).

25. J. R. Hallman. "Radiation Absorption for Polymers." Characterization of Metal and Polymer Surfaces 2, PP 429-446, Academic Press Inc., New York, NY (1977).

26. J. P. Holman. Heat Transfer. 4th ed., McGraw-Hill Book Company, New York, NY (1976). 